\title{
Article
}

\section{A novel mechanism regulating insulin secretion involving Herpud1 in mice}

N. Wong ${ }^{1}$, G. Morahan ${ }^{2}$, M. Stathopoulos ${ }^{1}$, J. Proietto $^{1}$ and S. Andrikopoulos ${ }^{1}$

${ }^{1}$ University of Melbourne, Department of Medicine (Austin Health), Austin Hospital, Heidelberg Heights, VIC 3084, Australia

${ }^{2}$ Centre for Diabetes Research, Western Australian Institute for Medical Research, Perth, WA, Australia

\section{Corresponding author}

N. Wong, University of Melbourne, Department of Medicine (Austin Health), Austin Hospital, Heidelberg Heights, VIC 3084, Australia

E-mail: $\quad$ wongn@unimelb.edu.au

Received: 26 October 2012 / Accepted: 18 March 2013 


\section{Abstract}

Aims/hypothesis Type 2 diabetes results from beta cell dysfunction after prolonged physiological stress, which causes oversecretion of insulin. We recently found that insulin hypersecretion is mediated by at least two genes. Among mouse models of type 2 diabetes, the DBA/2 mouse strain is more susceptible to diabetes than is the $\mathrm{C} 57 \mathrm{BL} / 6 \mathrm{~J}(\mathrm{~B} 6 \mathrm{~J})$ strain. One distinctive feature of the $\mathrm{DBA} / 2$ mouse is that it hypersecretes insulin, independent of changes in insulin sensitivity; we identified $N n t$ as a gene responsible for this trait.

Methods To identify the other gene(s) affecting insulin hypersecretion, we tested a panel of recombinant inbred BXD strains, which have different combinations of B6 and DBA/2 alleles. Results We found that $25 \%$ of the BXD strains hypersecreted insulin in response to glucose. Microarray profiling of islets from high- and low-secretor strains showed that at least four genes were differentially expressed. One gene was consistently underexpressed in islets from both DBA/2 and the high-secretor BXD strains. This gene (Herpudl or Herp) encodes the $54 \mathrm{kDa}$ endoplasmic reticulum stress-inducible protein (HERP) that resides in the integral endoplasmic reticulum membrane. To test directly whether Herpudl can interact with Nnt, Herpudl was either knocked down or overexpressed in MIN6 cells. These results showed that when Herpud1 was suppressed, $N n t$ expression was reduced, while overexpression of Herpudl led to increased Nnt expression. Furthermore, Herpudl suppression resulted in significantly decreased glucose-stimulated insulin secretion in the $\mathrm{DBA} / 2$ islets but not $\mathrm{B} 6 \mathrm{~J}$ islets.

Conclusions/interpretation We conclude that Herpudl regulates insulin secretion via control of Nnt expression.

\section{Keywords}

B6J, B6N, DBA/2, Diabetes susceptibility, Glucose-stimulated insulin secretion, Homeocysteineresponsive endoplasmic reticulum-resident ubiquitin-like domain member 1, Insulin Hypersecretion, Nicotinamide nucleotide transhydrogenase
Abbreviations
B6J
C57BL/6J
B6N C57BL/6N
ER Endoplasmic reticulum
ERAD ER-associated degradation
GWAS Genome-wide association studies
HERP Endoplasmic reticulum stress-inducible protein 
NNT Nicotinamide nucleotide transhydrogenase

RT-PCR Real-time polymerase chain reaction

SiRNA Small interfering RNA

UPR Unfolded-protein response 


\section{Introduction}

Type 2 diabetes results from a complex interplay between genetic and environmental factors, which lead to two pathophysiological defects-insulin resistance and impaired insulin secretion.

Hyperglycaemia caused by reduced insulin secretion results from beta cell dysfunction and/or loss. It is well established that a number of stressors, such as glucose toxicity, lipotoxicity and cytokine exposure, can contribute to this beta cell dysfunction/death [1-3]. However, the underlying molecular cause of beta cell dysfunction has not yet been fully defined. There is strong evidence that type 2 diabetes is a polygenic disease [4]. Recent genome-wide association studies (GWAS) have identified a number of risk genes, including TCF7L2, CDKAL1, HHEX, SLC30A8, $C D K N 2 A / B, I G F 2 B P 2, K C N J 11$ and many more [5]. It is important to note that the cases used in some of these GWAS were chosen for their early age of onset and severity of disease so may not be representative of the typical individual with type 2 diabetes. Therefore, these genes may only account for a small proportion of the genetic susceptibility of type 2 diabetes, so further studies are warranted to identify more genes contributing to the disease process.

While the exact cause of beta cell dysfunction in type 2 diabetes is not known, it is evident that stimulation of the beta cell to secrete insulin under conditions when it is already maximally stressed (e.g. obesity and insulin resistance) can lead to deterioration in cellular function [6]. The DBA/2 mouse strain is a model of diabetes susceptibility, as compared with the C57BL/6J (B6J) strain which is resistant to diabetes. When DBA/2 mice were subjected to metabolic stress by the mutation of the leptin receptor $(d b / d b)$, they developed overt diabetes with failure and death of the beta cells, whereas the same mutation in the B6J strain led to obesity, insulin resistance and islet hyperplasia [7]. We recently showed that a mechanism for beta cell failure following high glucose exposure of DBA/2 islets is oxidative stress [8]. We also reported that a distinctive feature of the $\mathrm{DBA} / 2$ islet is that it hypersecretes insulin in response to glucose both in vivo and in vitro, and this seems to be independent of changes in insulin sensitivity [9]. We conducted a genome-wide genetic scan and found that the glucose-induced insulin hypersecretion of the DBA/2 mouse is mediated by at least two genes, one of which was identified as the gene for nicotinamide nucleotide transhydrogenase located at the end of chromosome 13. Nnt is expressed in DBA/2 islets at levels more than fivefold higher than in islets from the B6J strain [10]. It is worth noting that B6J mice harbour a truncated Nnt allele, while DBA/2 mice have a full-length gene [10]. Identification of Nnt as a diabetes-susceptible gene in the DBA/2 strain led us to propose that beta cell stimulation could itself precipitate type 2 diabetes in susceptible individuals [6]. This was supported in a clinical setting: the ADOPT (A Diabetes Outcome Progressional Trial) study showed that in newly 
Diab-12-1654.R2

diagnosed individuals with type 2 diabetes those treated with insulin secretagogues (sulfonylureas) had worse glycaemic control and progressed to beta cell failure and monotherapy faster than those treated with insulin sensitisers [11].

However, from our previous studies it was not clear why $N n t$ was upregulated in the DBA/2 and not in the B6J strain $[10,12]$. A possible explanation could be that other unidentified gene(s) were involved in driving Nnt upregulation in the DBA/2 mouse. Therefore, the aim of this study was to identify other gene(s) associated with insulin hypersecretion. To do so, we used the recombinant inbred BXD strain set. The genomes of BXD strains are derived from the DBA/2 and B6J strains and have been extensively genotyped across all chromosomes, facilitating gene mapping and systems genetic studies [13-15]. 


\section{Methods}

Animals B6J and DBA/2 mice were purchased from The Walter and Eliza Hall Institute for Medical Research (WEHI, Kew, VIC, Australia). The B6J mice were acquired by WEHI from The Jackson Laboratory and re-derived at the WEHI animal facility in 1989. C57BL/6-NTac (B6N) mice were purchased from Taconic Farm (Germantown, NY, USA) and maintained at the BioResources Facility Austin Health (Heidelberg, VIC, Australia). BXD lines were maintained at the Animal Resources Centre (Murdoch, WA, Australia). All mice were fed a standard rodent control chow diet (74\% carbohydrate, $20 \%$ protein and 3\% fat by weight; Ridley AgriProducts, Pakenham, VIC, Australia). Experimental procedures were performed using male mice at 8 weeks of age. All procedures were approved by the Austin Health Animal Ethics Committee (AEC No.: A2007/03055, A2005/02110 and A2010/04104).

Intravenous glucose tolerance test, plasma glucose and insulin assays The mice were fasted overnight (approximately $16 \mathrm{~h}$ ) before the intravenous glucose tolerance test (IVGTT) as previously described [10]. Plasma glucose concentrations were measured using a GM7 Analyser (Analox Instruments, London, UK). Plasma insulin levels were determined by a rat specific insulin radioimmunoassay kit (Merck Millipore, Billerica, MA, USA).

Nicotinamide nucleotide transhydrogenase enzyme activity assay Pancreatic nicotinamide nucleotide transhydrogenase (NNT) enzyme activity was performed as previously described [10]. Islet NNT enzyme activity was determined using the Biovision $\mathrm{NADP}^{+} / \mathrm{NADPH}$ quantification kit (Cat. No. K347-100; BioVision Research Products, Milpitas, CA, USA). Approximately 20 mg of pancreatic tissue was weighed out for each assay, washed with cold PBS and then homogenised with $400 \mu \mathrm{l}$ of NADP/NADPH extraction buffer in a microcentrifuge tube. The samples were centrifuged at 14,000 rpm for $5 \mathrm{~min}$ and the extracted NADP/NADPH solution was transferred into new tubes. NADP cycling buffer and NADP cycling enzyme mix was added to each NADPH sample and incubated at room temperature for $5 \mathrm{~min}$ to convert NADP to NADPH. An NADPH developer was then added to each sample and developed for 1-4 h before reading the absorbance at $450 \mathrm{~nm}$. The final NADPH levels were calculated by a standard curve. All samples were performed in duplicate. For further details please refer to protocol provided by the supplier.

Gene knockdown and overexpression Herpud1 siRNAs (Cat. 4392421 ID: s82159 and s82160; please refer to electronic supplementary material [EMS] Table 1 for sequences) from Life Technologies (Melbourne, VIC, Australia) or pCMV.Sport6-Herpud1 vector (a pre-constructed 
plasmid expression vector containing Herpud1 mouse cDNA) from Invitrogen (Cat. 4236803) and Nnt (PCI.Neo-Nnt) [12] was transfected into islets or MIN6 cells by following the manufacturer's specification for Lipofectamine 2000 (Invitrogen, Mount Waverley, VIC, Australia) .

Insulin secretion assay The parental and transfected cells were preincubated in KRB with 2.8 $\mathrm{mmol} / \mathrm{l}$ glucose for $90 \mathrm{~min}$ and then stimulated for $60 \mathrm{~min}$ with either $2.8 \mathrm{mmol} / \mathrm{l}$ or $20 \mathrm{mmol} / \mathrm{l}$ glucose as previously described [16].

Pancreatic insulin content, islet isolation and cDNA preparation These techniques were performed as previously described $[10,12]$.

Gene expression microarray and analysis Total RNA was extracted from isolated islets and sample quality was verified by the Agilent Bioanalyser (Mulgrave, VIC, Australia). Complimentary RNA (cRNA) was generated from mRNA by the Illumina(r) TotalPrep RNA Amplification Kit from Life Technologies (Cat. AMIL1797). The cRNA was used for Whole-Genome Gene Expression by direct hybridisation following the manufacturer's specification (Illumina, Part: 11322355). The raw gene expression data was analysed using the Illumina Genome studio software. The candidate regions were selected by the genotype of the low- and high-secretor BXD strains using the publicly available genotype data set from the Gene Network [14]. More specifically, these are regions that were marked with B6J alleles in the low secretors and DBA/2 alleles in the high secretors. Genes that showed greater than a twofold difference from the microarray and located within these candidate regions were identified for further analysis.

Real-time PCR analysis Gene expression was determined using primers and probe (Taqman Gene Expression Assays) purchased from Applied Biosystems (Scoresby, VIC, Australia). The expression of 18S RNA was used as an endogenous control. Amplification and detection were performed with the ABI Prism 7700 Sequence Detector and Sequence Detection System software (version 1.9.1; Applied Biosystems). Each measurement was carried out in duplicate. Difference in gene expression was expressed as percentage of fold-change from control and was calculated using the $2^{-\Delta \Delta \mathrm{C}_{\mathrm{t}}}$ method using $18 \mathrm{~S}$ as the internal control.

Western blot analysis The expression of HERP protein in isolated islets was determined using western blot analysis as previously described [8]. The following antibodies from Abcam (Redfern, 
NSW, Australia) were used: anti-Herpud1 antibody (ab73669) and anti- $\alpha$-tubulin antibody (ab4074) as loading control.

Statistical analysis All data are expressed as mean \pm SEM from repeated experiments. The statistical analyses were determined by a two-tailed, unpaired (two-sample assuming equal variances) Student's $t$ test for parametric data. The level of statistical significance was taken as $p \leq 0.05$. 


\section{Results}

Characterisation of BXD strains We searched for gene(s) associated with insulin hypersecretion by performing an IVGTT on available BXD strains. Low and high secretors were defined as described previously [10]. Upon administration of glucose, four BXD lines (BXD-9, -11, -24 and -32) out of twenty that were available to us for testing, hypersecreted insulin at the 2 min time point, which is the peak of first phase in the insulin secretion test (Fig. 1a). This insulin hypersecretion was clearly independent of fasting plasma insulin (Fig. 1b) and fasting plasma glucose levels (Fig. 1c) because no correlation was observed among these traits in the BXD strains. As expected from our earlier study, the BXD strains that hypersecreted insulin all had DBA/2-derived alleles of $N n t$ [14]. However, it is important to note that not all of the BXD strains that had DBA/2 Nnt alleles hypersecreted insulin, clearly demonstrating the involvement of other gene(s) in controlling this trait. For example, BXD lines 6, 22, 28, 31 and 62 all had DBA/2-derived alleles at $64.0 \mathrm{cM}$ on chromosome 13 but all secreted insulin at levels similar to B6J. Insulin hypersecretion was predominantly associated with an increase in Nnt expression and NNT activity [10]. Consistent with these findings, the low-secretor strains BXD75 and 96 had lower NNT activity, similar to B6J, while the high secretors (BXD 9 and 11) had higher NNT activity, like DBA/2 controls (Fig. 2a), confirming that higher $N n t$ at least in part contributed to the insulin hypersecretion phenotype. Taken together, our data suggest that the BXD strains that failed to hypersecrete insulin despite having a DBA/2-derived $N n t$ allele lacked critical regulatory factor(s) for facilitating $N n t$ expression.

Differential gene expression between high-and low-secretor strains To identify genes associated with altered Nnt levels, we employed a systems genetics approach [17], integrating genetic and gene expression information. We reasoned that all high-secretor strains would share DBA/2 alleles of these genes while all low-secretor strains would have B6J-derived alleles. With the information that we were able to use from the relatively small number of BXD strains that we had access to, we found candidate regions on chromosomes 2, 3, 4, 5, 6, 8, 9, 12, 13, 14 and16 (Fig. 2b) for further analysis.

Next, a series of microarrays was performed and the differential gene expression profile in the pancreatic islets determined. Genes that showed greater than a twofold difference in expression and positioned within the candidate regions were identified. These analyses showed eight candidate genes that were differentially expressed between the high- and low-secretor strains (Table 1). Four genes, namely, frizzled-related protein ( $F r z b$; chromosome 2), nuclear factor, interleukin3 (Nfil3; 
chromosome 13), coagulation factor II ( $F 2 r$; chromosome 13) and homeocysteine-inducible, endoplasmic reticulum stress-inducible, ubiquitin-like domain member 1 (Herpud1; chromosome 8), were selected for further investigation based on their known function. Real-Time PCR (RTPCR) was then performed to confirm the level of gene expression. Only one gene, Herpudl (also called Herp), was consistently underexpressed in both the high-secretor BXD strains and DBA/2 mouse islets (Fig. 3a-d). HERP protein levels were also lower in DBA/2 than in B6J islets (Fig. 3e). Herpudl encodes HERP, a $54 \mathrm{kDa}$ protein that resides in the integral endoplasmic reticulum (ER) membrane [18]. However, the role of Herpudl in pancreatic beta cells has not been fully defined.

Characterisation of Herpudl To determine whether Herpudl has a role in regulating Nnt expression, it was either knocked down or overexpressed in the pancreatic MIN6 cell line and RTPCR was performed to determine gene expression levels. If Herpudl plays a role in regulating Nnt expression, altering its expression should also affect expression levels of Nnt. Using two sets of siRNA oligonucleotides, we found a reduction in the expression levels of both Herpudl and Nnt (Fig. 4a). Conversely, Herpudl overexpression in MIN6 cells led to increased Nnt expression (Fig. 4b). In addition, increasing Nnt by gene overexpression in MIN6 cells suppressed Herpud1 expression (Fig. 4c,d), suggesting a reciprocal regulation between Herpudl and Nnt. Furthermore, a plot between Herpudl and Nnt revealed a positive correlation between these two genes in DBA/2, but not B6J, islets (Fig. 4e). An unexpected finding of this study was that Herpud1 mRNA levels were higher in B6J than in DBA/2. This may have been due to the 5-exon deletion mutation in the B6J Nnt allele [10] with feedback causing higher Heprudl expression. Taken together, these data provide the first direct evidence for an interaction between these two genes, with Herpud1 regulating $N n t$ expression.

We next knocked down Herpudl using the same set of siRNA oligonucleotides in isolated B6J and $\mathrm{DBA} / 2$ islets, and insulin secretion was determined. The results showed that there was no difference in insulin secretion between the siRNA-negative control and Herpudl siRNA-treated B6J islets (Fig. 5a). However, a significant decrease in insulin secretion was observed in the Herpud1 siRNAtreated DBA/2 islets stimulated at $20 \mathrm{mmol} / \mathrm{l}$ glucose (Fig. 5a). Insulin content was also assessed in these islets to determine whether the decrease in insulin secretion was due to a functional defect. The results, although not statistically significant, showed that the total insulin content was in fact trending towards an increase in the DBA/2 islets following the knockdown of Herpudl (Fig. 5b). We also attempted to measure HERP protein levels in islets treated with siRNA; however, the western blot technique may not have been sensitive enough to produce reliable results. Nonetheless, 
Diab-12-1654.R2

RT-PCR and NNT activity assay was also performed on these islets to confirm the gene knockdown of Herpudl and, again, the data showed that reducing Herpudl also reduced Nnt expression (Fig. 5c) and NNT activity (Fig. 5d).

We investigated whether the difference between the response of B6J and DBA/2 could be due to the $N n t$ exonic deletion in the latter strain. To do so, we compared the effect of upregulation of Herpud1 on insulin secretion in B6J and the C57BL/6N (B6N) substrain, which possesses the fulllength NNT gene [12]. The results showed that transient 24 h overexpression of Herpudl led to similar Herpud1 expression levels in the B6J and B6N islets (Fig. 5e). However, Nnt upregulation was only detected in $\mathrm{B} 6 \mathrm{~N}$ islets and not $\mathrm{B} 6 \mathrm{~J}$ islets (Fig. 5e). We confirmed that overexpressing Herpudl in islets increased HERP protein levels using western blotting (Fig. 5f). Consistent with these results, Herpudl overexpression led to no change in glucose-stimulated insulin secretion in the B6J islets (Fig. 5g). However, the B6N islets showed a significant increase in insulin secretion, similar to that seen in the DBA/2 islets (Fig. 5e). Taken together, our data demonstrate that Herpudl not only regulated Nnt expression but also had a functional effect in the pancreatic beta cell. 


\section{Discussion}

It is well established that beta cell dysfunction leads to hyperglycaemia in type 2 diabetes. Despite many years of effort, the exact cause of beta cell dysfunction is still not fully understood, although environmental factors in a permissive genetic environment are expected to be involved.

Since genetic susceptibility is predetermined, understanding type 2 diabetes genetics is vital in developing new therapeutic targets to treat and prevent this disease. There is accumulating evidence to suggest that overstimulating the beta cell may be an important risk factor in the development of its dysfunction: some individuals with obesity and a family history of type 2 diabetes, who are at increased risk of developing the condition, paradoxically hypersecrete insulin. In support of this, a variant in the sulfonylurea receptor gene (SUR1, also known as ABCC8) resulting in elevated fasting and glucose-induced plasma insulin concentrations has been described in non-diabetic Mexican Americans, an ethnic group with a high incidence of type 2 diabetes [19]. Moreover, it was shown in Pima Indians, who have the highest incidence of diabetes of any ethnic group in the world, that fasting hyperinsulinaemia was a significant predictor of the disease, independent of insulin resistance [20]. Primary defects causing insulin hypersecretion can also lead to beta cell dysfunction; for example, patients with a mutation in the $G C K$ gene develop persistent hyperinsulinaemic hypoglycaemia of infancy and diabetes requiring insulin later in life [21]. We have previously reported that increased Nnt gene expression was associated with insulin hypersecretion in the DBA/2 mouse. However, the transcription regulation mechanism of Nnt was not yet known. Here we have identified Herpudl, which not only regulates the expression of Nnt but can also modulate insulin secretion in the pancreatic beta cell. Herpudl is a mammalian ubiquitin domain-containing protein, which is highly induced by the unfolded-protein response (UPR) in response to ER stress. However, its function in insulin secretion in the pancreatic beta cell has not previously been investigated. Recent studies on Herpudl revealed an important role for this gene in facilitating the ER-associated degradation (ERAD) system in the ER. For example, Herpudl was shown to interact with members of the ubiquitin family and functions as a shuttle factor to deliver ubiquitinated substrates to the proteasome for degradation [22]. Similarly, Herpudl was found to be involved in the regulation of Hrd1 ubiquitinylation, a ubiquitin-ligase complex responsible for rapid protein degradation in the ER [23]. Others showed that HERP was required for linking BiP substrates with the proteasome for target protein degradation [24]. Also, HERP can function as a substitute for Usa1p, a yeast protein that has a well established role in the ERAD system [25].

Although HERP was identified as a stress-responsive protein, evidence suggests that it can behave differently in different tissues. Interestingly, unlike other ER stress-induced molecules residing in 
the ER lumen, a major portion of the HERP molecule is present on the cytoplasmic side of the ER membrane [18]. Therefore, it has been suggested that HERP may have a role distinct from that of molecular chaperones. In fact, evidence suggests that the ubiquitin-like domain of HERP could have diverse roles. For example, using a human embryonic cell line, HERP was reported to be involved in the generation of amyloid beta proteins found in Alzheimer's disease [26]. Others showed that Herpudl was upregulated by Wnt-1 signalling, which regulates morphogenesis and mitogenesis in both murine and human colorectal cells [27]. Moreover, Herpudl was also shown to play a significant role in regulating $\mathrm{Ca}^{2+}$ homeostasis as well as mitochondrial function in neuronal cell cultures [28], while others suggested that it might be involved in the immune system [29]. Taken together, the above evidence suggests that Herpudl has a wide range of biological functions, although the role of this gene in the beta cell remains to be elucidated. A recent study reported that Herpudl null mice had impaired glucose tolerance, which appeared to be independent of insulin sensitivity [30]. Interestingly, these mice were produced on a C57BL/6CrSlc background, a substrain of C57BL/6 that carries the full-length Nnt [31]. It was unclear how Herpud1 deficiency led to impaired glucose tolerance but since insulin sensitivity was not affected it is possible that there may be an insulin secretory defect. Although neither insulin secretion nor the expression of $N n t$ was assessed in these animals, this study highlights the importance of Herpudl in glucose homeostasis. More importantly, our study provides the first direct evidence to show a functional role for Herpudl in insulin secretion and that this could be mediated through the Nnt gene. Exactly how Herpudl regulates Nnt expression is not clear, although it appears that the full-length $N n t$ is required for this regulation to be effective. It is also possible that the effects of Herpudl on insulin secretion may be implicated by the indirect effects of this UPR target protein on the expression and function of other proteins involved in the secretory pathway. In addition, there are also strain differences between B6 and DBA/2, such as insulin secretion, islet mass and diabetes susceptibility, which may also contribute to the phenotype $[8,10,32,33]$. However, it is worth noting that the effects of Herpudl on insulin secretion were observed in two different animal models (i.e. DBA/2 and $\mathrm{B} 6 \mathrm{~N})$, therefore the effects of Herpudl on insulin secretion are likely to be independent of strain variations. Instead, it is possible that the ubiquitin-like domain sequence in Herpudl, which can have diverse functions, may act as a transcriptional factor to alter Nnt levels, with subsequent changes in insulin secretion. In addition, the function of Herpudl in $\mathrm{Ca}^{2+}$ homeostasis may also be a mechanism for the regulation of Nnt, leading to secretory changes. Moreover, significant quantitative trait loci on chromosome 8 for glucose intolerance and pancreatic beta cell function have also been reported in human and rodent studies $[34,35]$. In conclusion, our data not only 
Diab-12-1654.R2

present a new role for Herpudl in beta cell function but are also the first to show that Herpudl has a functional effect in the regulation of insulin secretion in the pancreatic islet. 


\section{Acknowledgements}

We are grateful for the excellent technical assistance of Z. Ruan, A. Huang, A. Blair and C.

Rantzau from the University of Melbourne for assisting with the experimental procedures.

\section{Funding}

This study was supported by the National Health Medical Research Council and Diabetes Australia Research Trust. The systems genetics study was supported by funding from the University of Western Australia, the Diabetes Research Foundation (WA) and NHMRC Program Grant 53000400.

\section{Duality of interest}

The authors declare that there is no duality of interest associated with this manuscript.

\section{Contribution statement}

NW contributed to the conception and design, acquisition of data, data interpretation and analysis, and drafting the article and revising it critically for important intellectual content. GM, MS and JP were responsible for acquisition of data, analysis and interpretation of data and revising the article. SA contributed to the design and conception of the study, data analysis and interpretation and assisted in drafting and critically revising the article. All authors approved the final version. 


\section{References}

1. Laybutt DR, Sharma A, Sgroi DC, Gaudet J, Bonner-Weir S, Weir GC (2002) Genetic regulation of metabolic pathways in beta-cells disrupted by hyperglycemia. J Biol Chem 277: 10912-10921

2. Lupi R, Dotta F, Marselli L, et al. (2002) Prolonged exposure to free fatty acids has cytostatic and pro-apoptotic effects on human pancreatic islets: evidence that beta-cell death is caspase mediated, partially dependent on ceramide pathway, and Bcl-2 regulated. Diabetes 51: 1437-1442

3. Pratley RE, Wilson C, Bogardus C (1995) Relation of the white blood cell count to obesity and insulin resistance: effect of race and gender. Obes Res 3: 563-571

4. Kaku K, Fiedorek FT, Jr., Province M, Permutt MA (1988) Genetic analysis of glucose tolerance in inbred mouse strains. Evidence for polygenic control. Diabetes 37: 707-713

5. Kirchhoff K, Machicao F, Haupt A, et al. (2008) Polymorphisms in the TCF7L2, CDKAL1 and SLC30A8 genes are associated with impaired proinsulin conversion. Diabetologia 51: 597-601 6. Andrikopoulos S (2010) Obesity and type 2 diabetes: slow down!--Can metabolic deceleration protect the islet beta cell from excess nutrient-induced damage? Mol Cell Endocrinol 316: $140-146$

7. Leiter EH, Coleman DL, Hummel KP (1981) The influence of genetic background on the expression of mutations at the diabetes locus in the mouse. III. Effect of H-2 haplotype and sex. Diabetes 30: 1029-1034

8. Zraika S, Aston-Mourney K, Laybutt DR, et al. (2006) The influence of genetic background on the induction of oxidative stress and impaired insulin secretion in mouse islets. Diabetologia 49: 1254-1263

9. Kooptiwut S, Zraika S, Thorburn AW, et al. (2002) Comparison of insulin secretory function in two mouse models with different susceptibility to beta-cell failure. Endocrinology 143: 2085-2092

10. Aston-Mourney K, Wong N, Kebede M, et al. (2007) Increased nicotinamide nucleotide transhydrogenase levels predispose to insulin hypersecretion in a mouse strain susceptible to diabetes. Diabetologia 50: 2476-2485

11. Viberti G, Kahn SE, Greene DA, et al. (2002) A diabetes outcome progression trial (ADOPT): an international multicenter study of the comparative efficacy of rosiglitazone, glyburide, and metformin in recently diagnosed type 2 diabetes. Diabetes Care 25: 1737-1743 
12. Wong N, Blair AR, Morahan G, Andrikopoulos S (2010) The deletion variant of nicotinamide nucleotide transhydrogenase (Nnt) does not affect insulin secretion or glucose tolerance. Endocrinology 151: 96-102

13. Taylor B (1989) Recombinant inbred strains. In: Lyon ML, Searle AG (eds) Genetic variants and strains of the laboratory mouse, 2nd edn. Oxford University Press, Oxford, pp 773-796 14. BXD Genotypes Database www.genenetwork.org/dbdoc/BXDGeno.html (2003), accessed 12 March 2013

15. Peirce JL, Lu L, Gu J, Silver LM, Williams RW (2004) A new set of BXD recombinant inbred lines from advanced intercross populations in mice. BMC Genet 5: 7

16. Kebede M, Favaloro J, Gunton JE, et al. (2008) Fructose-1,6-bisphosphatase overexpression in pancreatic beta-cells results in reduced insulin secretion: a new mechanism for fat-induced impairment of beta-cell function. Diabetes 57: 1887-1895

17. Morahan G, Williams RW (2007) Systems genetics: the next generation in genetics research? Novartis Found Symp 281: 181-188; discussion 188-191, 208-189

18. Kokame K, Agarwala KL, Kato H, Miyata T (2000) Herp, a new ubiquitin-like membrane protein induced by endoplasmic reticulum stress. J Biol Chem 275: 32846-32853

19. Goksel DL, Fischbach K, Duggirala R, et al. (1998) Variant in sulfonylurea receptor-1 gene is associated with high insulin concentrations in non-diabetic Mexican Americans: SUR-1 gene variant and hyperinsulinemia. Hum Genet 103: 280-285

20. Weyer C, Hanson RL, Tataranni PA, Bogardus C, Pratley RE (2000) A high fasting plasma insulin concentration predicts type 2 diabetes independent of insulin resistance: evidence for a pathogenic role of relative hyperinsulinemia. Diabetes 49: 2094-2101

21. Glaser B, Kesavan P, Heyman M, et al. (1998) Familial hyperinsulinism caused by an activating glucokinase mutation. N Engl J Med 338: 226-230

22. Kim TY, Kim E, Yoon SK, Yoon JB (2008) Herp enhances ER-associated protein degradation by recruiting ubiquilins. Biochem Biophys Res Commun 369: 741-746

23. Kny M, Standera S, Hartmann-Petersen R, Kloetzel PM, Seeger M (2011) Herp regulates Hrd1-mediated ubiquitylation in a ubiquitin-like domain-dependent manner. J Biol Chem 286: $5151-5156$

24. Okuda-Shimizu Y, Hendershot LM (2007) Characterization of an ERAD pathway for nonglycosylated BiP substrates, which require Herp. Mol Cell 28: 544-554

25. Carvalho P, Goder V, Rapoport TA (2006) Distinct ubiquitin-ligase complexes define convergent pathways for the degradation of ER proteins. Cell 126: 361-373 
26. Sai X, Kawamura Y, Kokame K, et al. (2002) Endoplasmic reticulum stress-inducible protein, Herp, enhances presenilin-mediated generation of amyloid beta-protein. J Biol Chem 277: 12915-12920

27. Chtarbova S, Nimmrich I, Erdmann S, et al. (2002) Murine Nr4a1 and Herpud1 are upregulated by Wnt-1, but the homologous human genes are independent from beta-catenin activation. Biochem J 367: 723-728

28. Chan SL, Fu W, Zhang P, et al. (2004) Herp stabilizes neuronal Ca2+ homeostasis and mitochondrial function during endoplasmic reticulum stress. J Biol Chem 279: 28733-28743 29. Hirabayashi Y, Oka Y, Ikeda T, et al. (2010) The endoplasmic reticulum stress-inducible protein, Herp, is a potential triggering antigen for anti-DNA response. J Immunol 184: 3276-3283 30. Eura Y, Yanamoto H, Arai Y, Okuda T, Miyata T, Kokame K (2012) Derlin-1 deficiency is embryonic lethal, Derlin-3 deficiency appears normal, and Herp deficiency is intolerant to glucose load and ischemia in mice. PLoS One 7: e34298

31. Mekada K, Abe K, Murakami A, et al. (2009) Genetic differences among C57BL/6 substrains. Exp Anim 58: 141-149

32. Bock T, Pakkenberg B, Buschard K (2005) Genetic background determines the size and structure of the endocrine pancreas. Diabetes 54: 133-137

33. Davis RC, van Nas A, Castellani LW, et al. (2012) Systems genetics of susceptibility to obesity-induced diabetes in mice. Physiol Genomics 44: 1-13

34. An P, Freedman BI, Rich SS, et al. (2006) Quantitative trait loci on chromosome 8q24 for pancreatic beta-cell function and 7q11 for insulin sensitivity in obese nondiabetic white and black families: evidence from genome-wide linkage scans in the NHLBI Hypertension Genetic Epidemiology Network (HyperGEN) study. Diabetes 55: 551-558

35. Suto J, Sekikawa K (2002) A quantitative trait locus that accounts for glucose intolerance maps to chromosome 8 in hereditary obese KK-A(y) mice. Int J Obes Relat Metab Disord 26: 15171519 


\section{Figure legends}

Fig. 1 BXD lines 9, 11, 24 and 32 hypersecreted insulin independent of changes in fasting plasma insulin and glucose level Plasma insulin concentrations at 2 min (a), fasting plasma insulin concentrations (b), and fasting glucose levels (c) during an IVGTT (1 g/kg glucose bolus) in 8- to 10-week-old B6J, DBA/2 and BXD strains. Results are presented as means \pm SEM ( $n=4-10)$. $* p<0.05$ vs B6J. White bars indicate high secretors

Fig. 2 NNT enzyme activity is enhanced in the high-secretor BXD strains, which may be associated with gene(s) located in several chromosomal hotspot regions. (a) Pancreatic NNT activity level in 8- to 10-week-old B6J, DBA/2 and BXD strains 75, 96, 11 and 9. Results are presented as means \pm SEM ( $n=4-10)$. * $p<0.05$ vs B6J. AcPy, 3-acetylpyridine analogue of NADH. (b) A schematic diagram of the hotspot locations on the chromosomes

Fig. 3 Herpudl is consistently underexpressed in islets from high-secretor B6J and from DBA/2 mice. mRNA levels of Frzb (a), Nfil3 (b), F2r (c) and Herpud1 (d) in islets from B6J, DBA/2, BXD 22 (low secretor) and BXD 11 (high secretor). (e) Representative western blot for HERP in islets isolated from B6J and DBA/2 mice. Results are presented as means $\pm \operatorname{SEM}(n=5)$. ${ }^{*} p<0.05$ vs B6J

Fig. 4 Downregulation of Herpudl resulted in reduced $N n t$ mRNA levels while overexpression elevated Nnt in a one-directional manner suggesting that Herpudl is upstream of Nnt. (a) mRNA levels of Herpudl (black bars) and Nnt (white bars) in MIN6 cells 24 h post knockdown of Herpudl using siRNA. Results are presented as means \pm SEM ( $n=5$ or 6 ). ${ }^{*} p<0.05$ vs control. (b) mRNA levels of Herpudl (black bars) and Nnt (white bars) in MIN6 cells $24 \mathrm{~h}$ following overexpression of Herpud1. Results are presented as means \pm SEM ( $n=5$ or 6 ). ${ }^{*} p<0.05$ vs control. (c) mRNA levels of Nnt in MIN6 cells $24 \mathrm{~h}$ following overexpression of Nnt. Results are presented as means \pm SEM ( $n=5$ or 6 ). ${ }^{*} p<0.05$ vs control. (d) RNA levels of Herpudl in MIN6 cells $24 \mathrm{~h}$ following overexpression of $N n t$. Results are presented as means $\pm \operatorname{SEM}(n=5$ or 6$)$. ${ }^{*} p<0.05$ vs control. (e) Correlation of Herpudl and Nnt gene expression in islets from B6 mice (black squares), $R^{2}=0.0472$ and DBA/2 mice (white squares), $R^{2}=0.8101$. Data presented as absolute values $(n=4)$

Fig. 5 HERP knockdown significantly impaired insulin secretion in islets expressing the fulllength Nnt while overexpression of Herpudl led to enhanced insulin secretion. (a) Insulin secretion in B6J and DBA/2 islets under low (2.8 mmol/l; $2.8 \mathrm{G})$ and high $(20 \mathrm{mmol} / 1 ; 20 \mathrm{G})$ glucose $48 \mathrm{~h}$ post treatment with scrambled control (siRNA-neg) or Herpudl siRNA. Results are presented as 
Diab-12-1654.R2

means \pm SEM ( $n=5$ or 6$) . * p<0.05$ vs siRNA-neg. (b) Insulin content in B6J and DBA/2 islets $48 \mathrm{~h}$ post treatment with scrambled control (siRNA-neg) or Herpudl siRNA. Results are presented as means \pm SEM ( $n=5$ or 6$) .{ }^{*} p<0.05$ vs siRNA-neg. (c) Herpudl (black bars) and Nnt (white bars) mRNA in B6J and DBA/2 islets following treatment with scrambled control (siRNA-neg) or Herpud1 siRNA. Results are presented as means \pm SEM ( $n=5$ or 6$) .{ }^{*} p<0.05$ vs siRNA-neg. (d) Islet NNT enzyme activity 48 h post Herpudl siRNA treatment in B6J and DBA/2 islets. Results are presented as means \pm SEM ( $n=5$ or 6 ). ${ }^{*} p<0.05$ vs siRNA-neg. (e) Herpudl and Nnt mRNA level 24 h post overexpression of Herpud1 in B6J (black bars) and B6N (white bars) islets. Results are presented as means \pm SEM ( $n=5$ or 6 ). ${ }^{*} p<0.05$ vs siRNA-neg. (f) Representative western blots of HERP in islets from B6J and B6N overexpressing Herpud1 (Herpud1) vs control (Neg). (g) Insulin secretion in B6J and B6N islets under low $(2.8 \mathrm{mmol} / \mathrm{l})$ and high $(20 \mathrm{mmol} / \mathrm{l})$ glucose $24 \mathrm{~h}$ post overexpression of Herpud1. Results are presented as means \pm SEM ( $n=5$ or 6$)$. ${ }^{*} p<0.05$ vs control, ${ }^{\dagger} p<0.05$ vs B6J 
Table 1 Chromosomal location and microarray expression value of eight candidate genes associated with insulin hypersceretion

\begin{tabular}{|l|l|l|l|}
\hline Chromosome & Location & Gene & Value \\
\hline 2 & $2 \mathrm{C} 3 ; 2$ & Frzb & 5.06 \\
\hline 5 & $5 \mathrm{G} 2 ; 5$ & Actb & 3.75 \\
\hline 6 & $6 \mathrm{E} 3 ; 6$ & Depp & 2.88 \\
\hline 8 & $8 \mathrm{~B} 3.1 ; 8$ & Sc4mol & 2.89 \\
\hline 8 & $8 \mathrm{C} 5 ; 8$ & Herpudl & 2.54 \\
\hline 12 & $12 \mathrm{E} ; 12$ & Ifi27l2a & 3.19 \\
\hline 13 & $13 \mathrm{~B} 1 ; 13$ & Nfil3 & 2.77 \\
\hline 13 & $13 \mathrm{D} 1 ; 13$ & F2r & 2.33 \\
\hline
\end{tabular}

Value, change in gene expression in low vs high secretors 


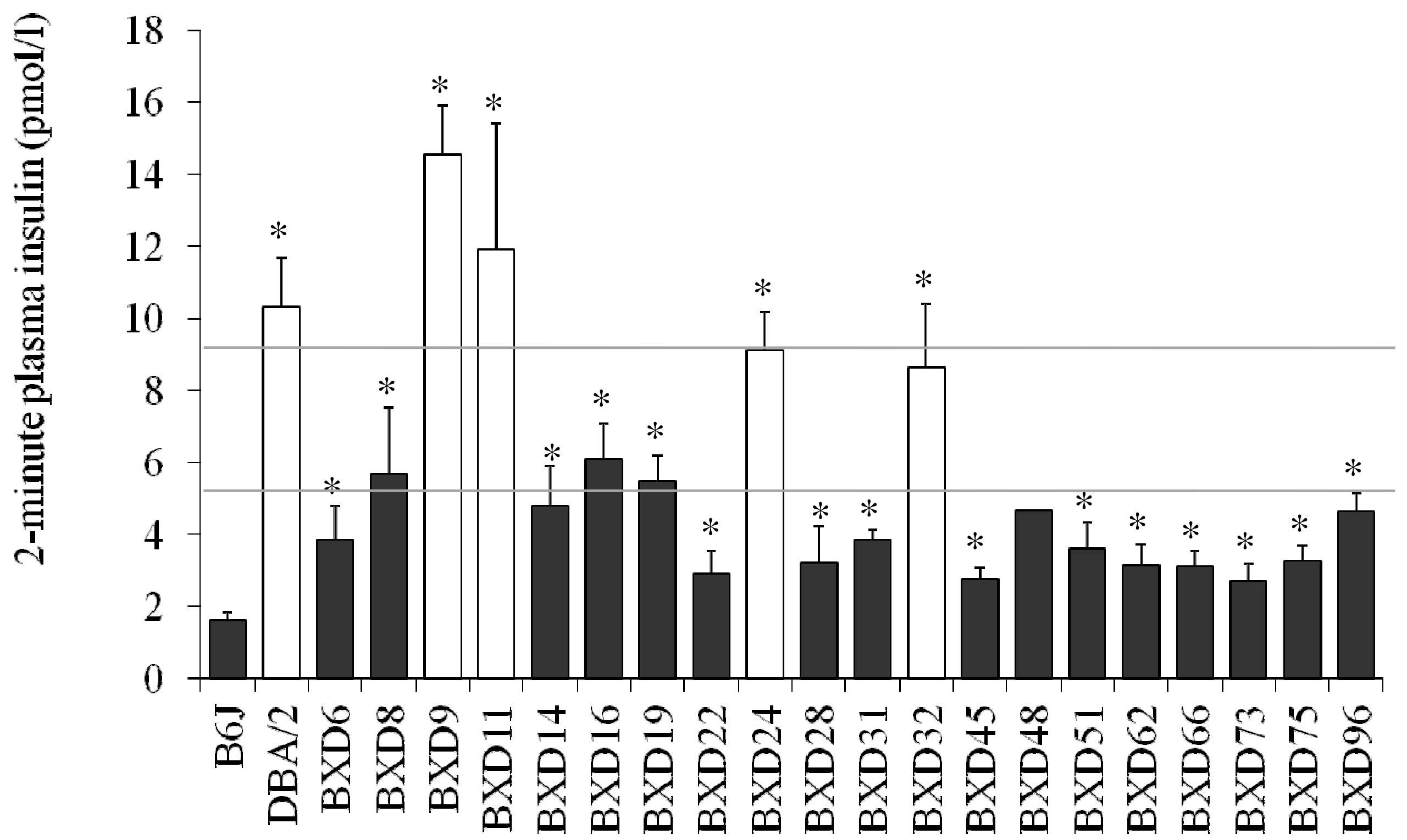

Figure 1 
b



Figure 1 


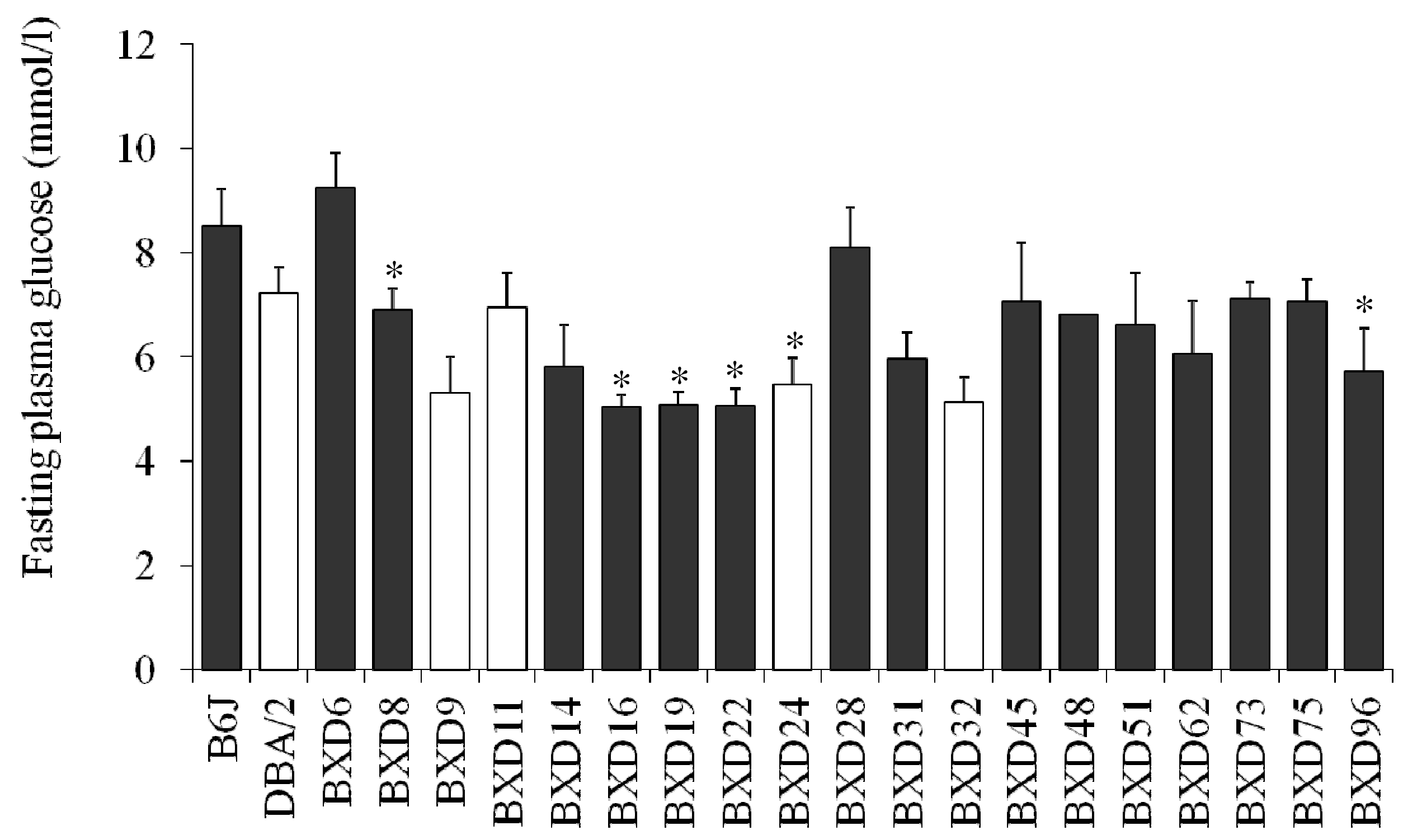

Figure 1 


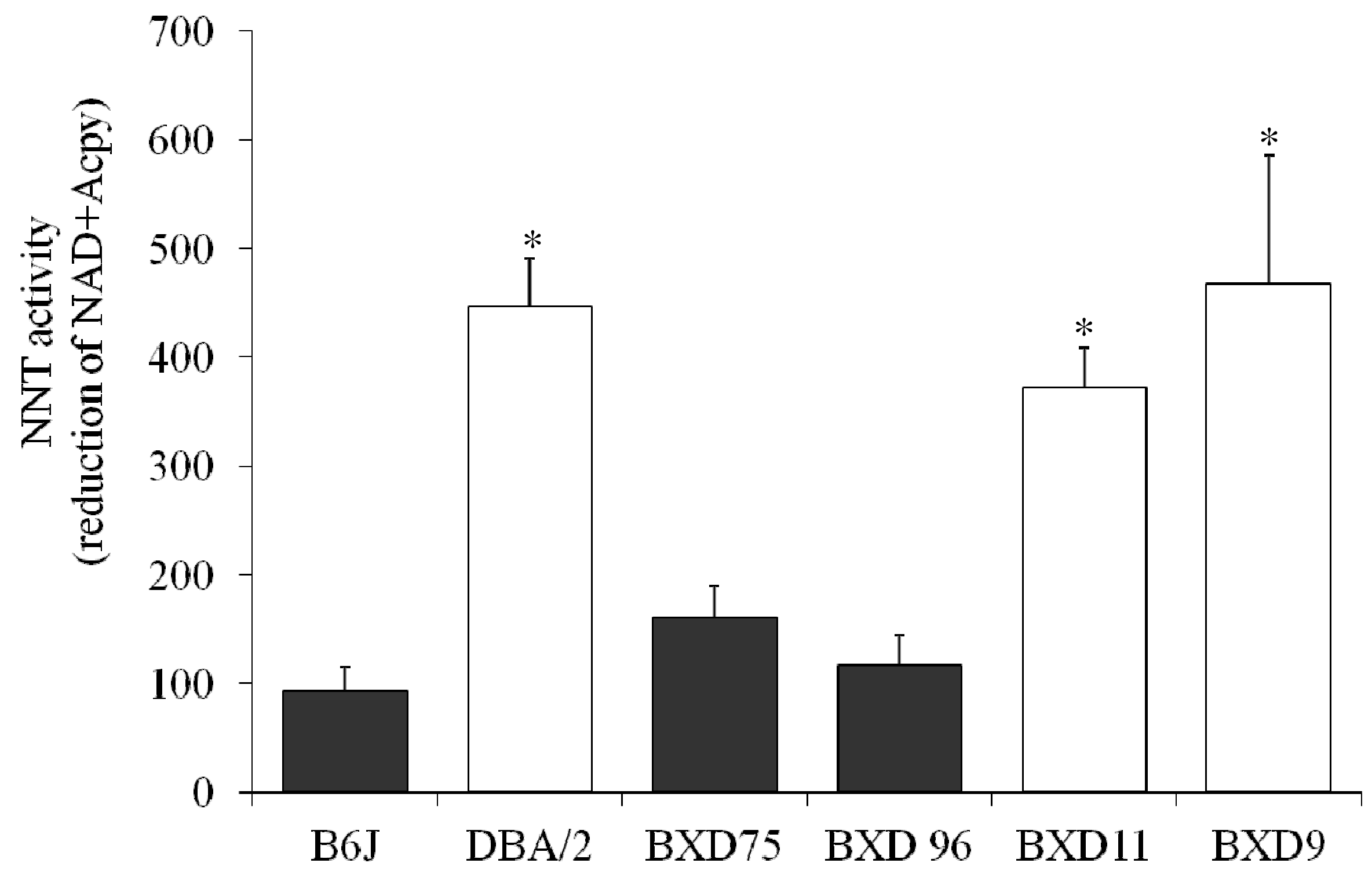

Figure 2 
b


12

13

14

15

16

17

18

19

X

Y

Figure 2 
a

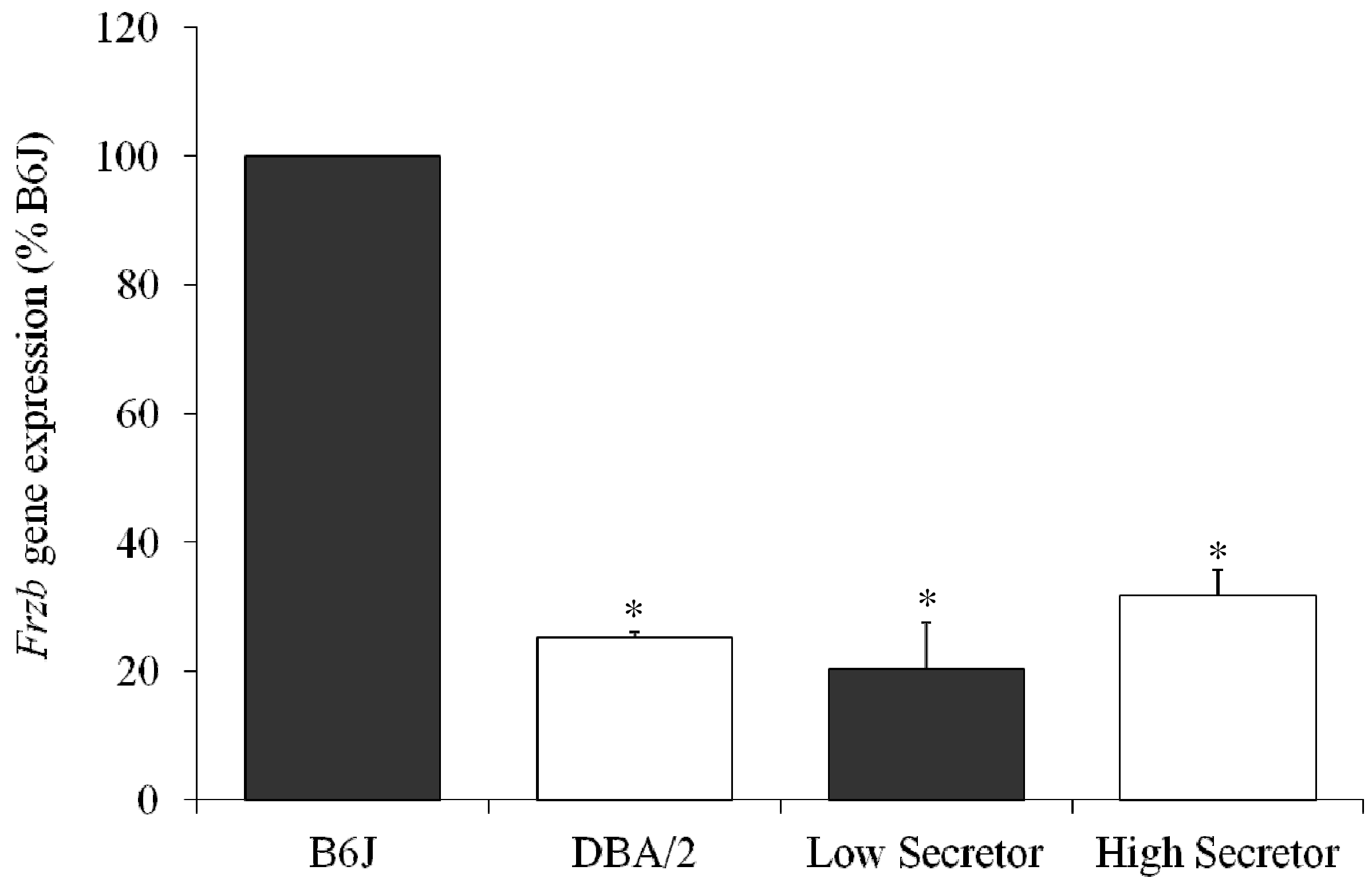

Figure 3 




Figure 3 


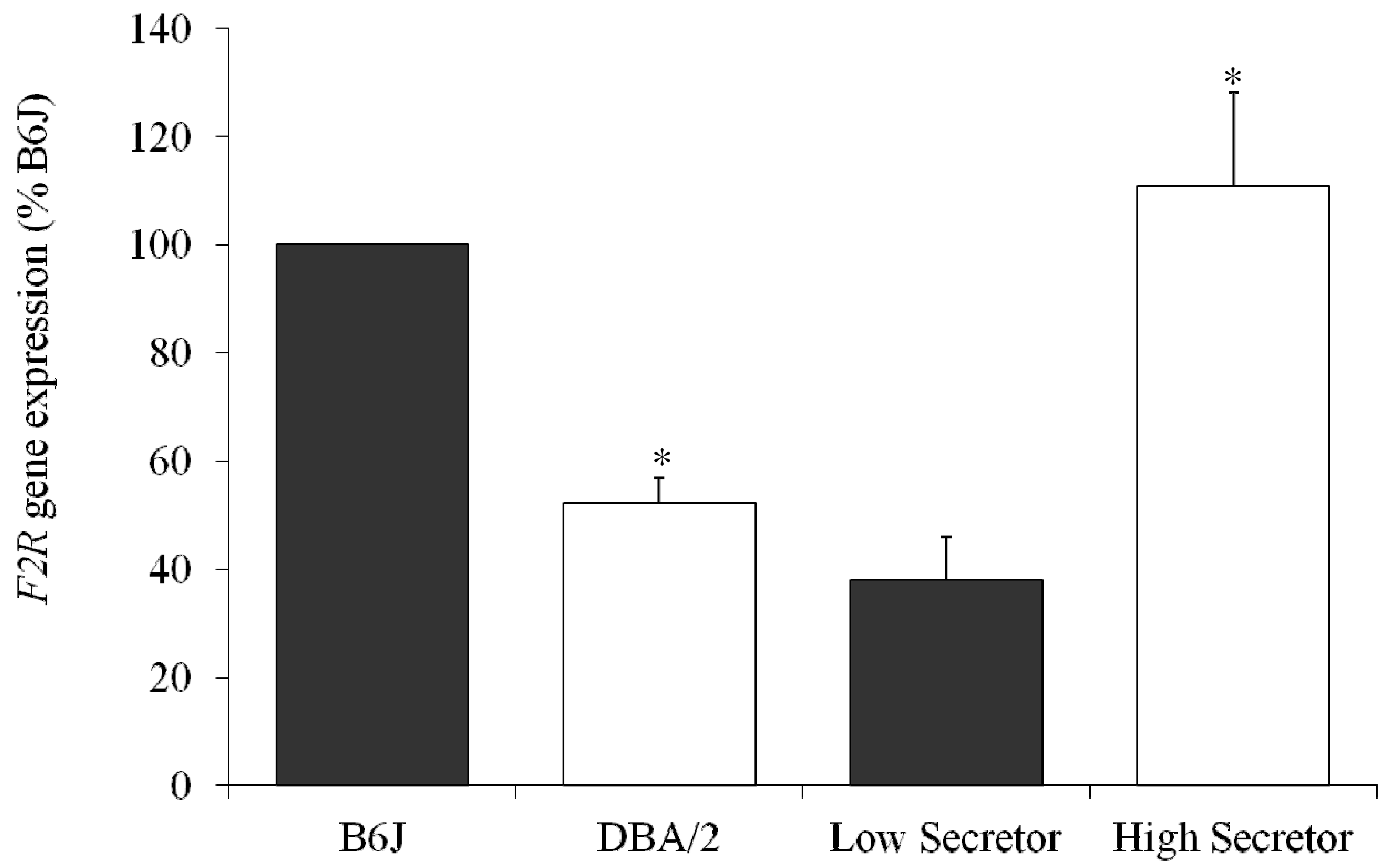

Figure 3 




Figure 3 
e

B6J DBA/2

44 kDa HERP

$50 \mathrm{kDa} \alpha$-tubulin

Figure 3 


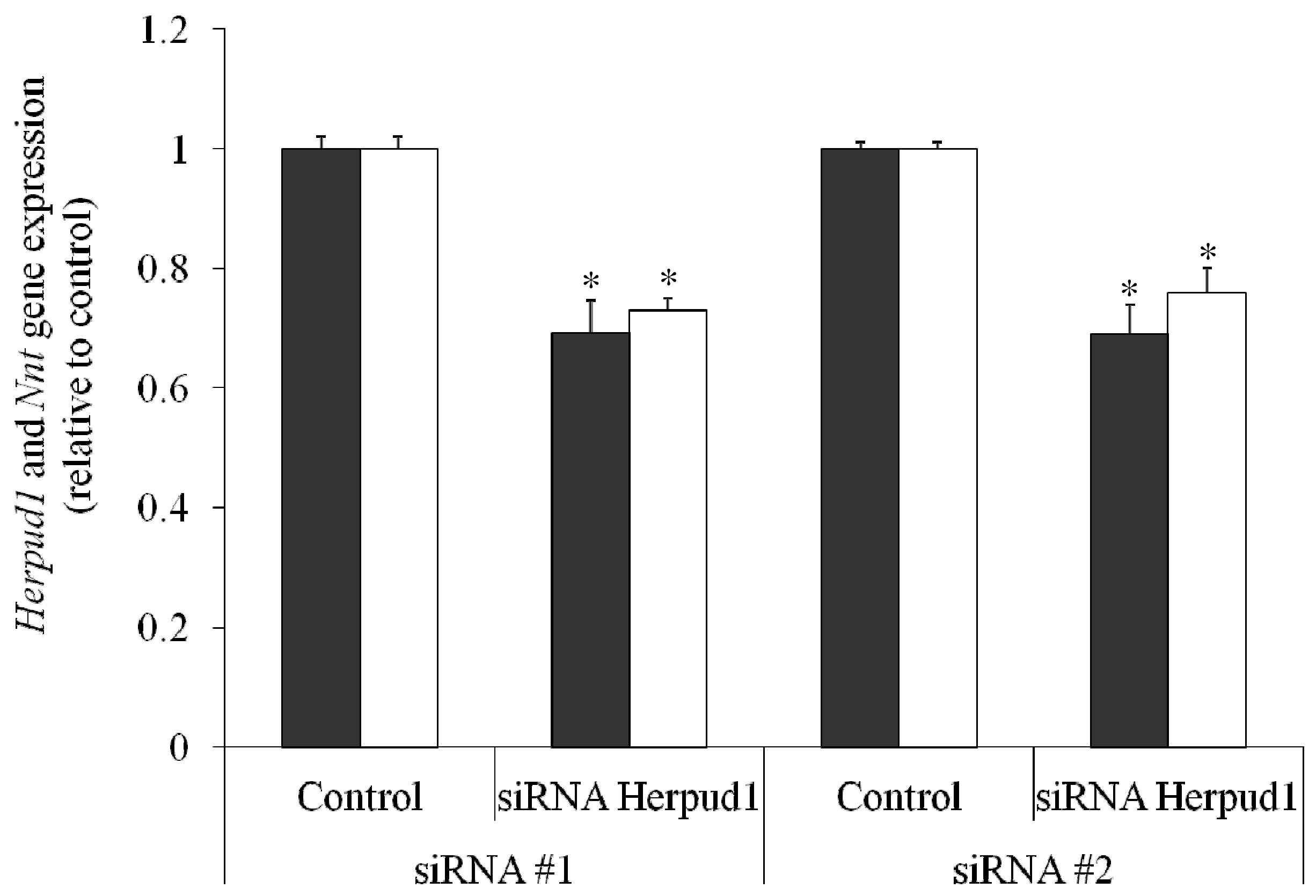

Figure 4 


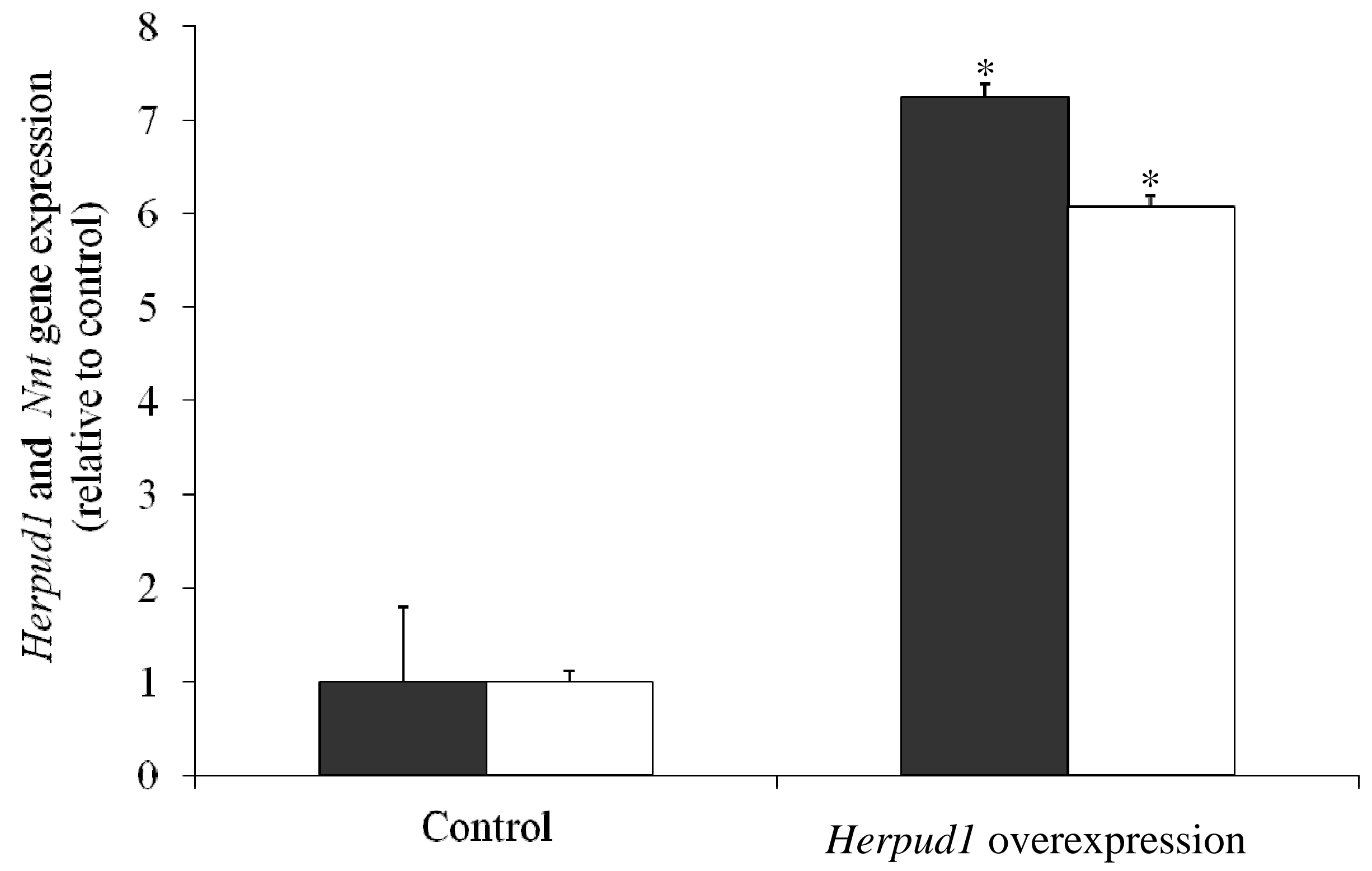

Figure 4 


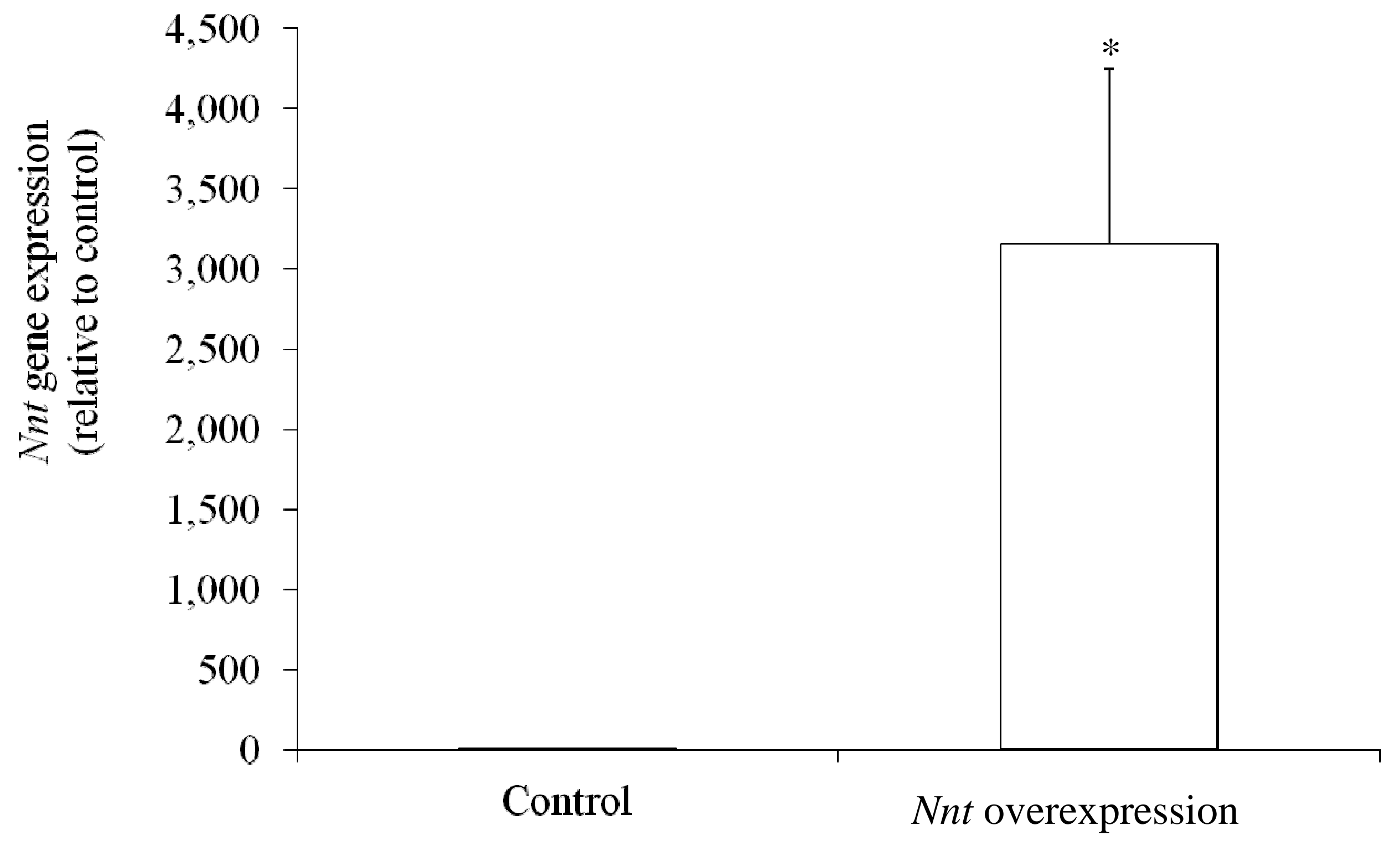

Figure 4 


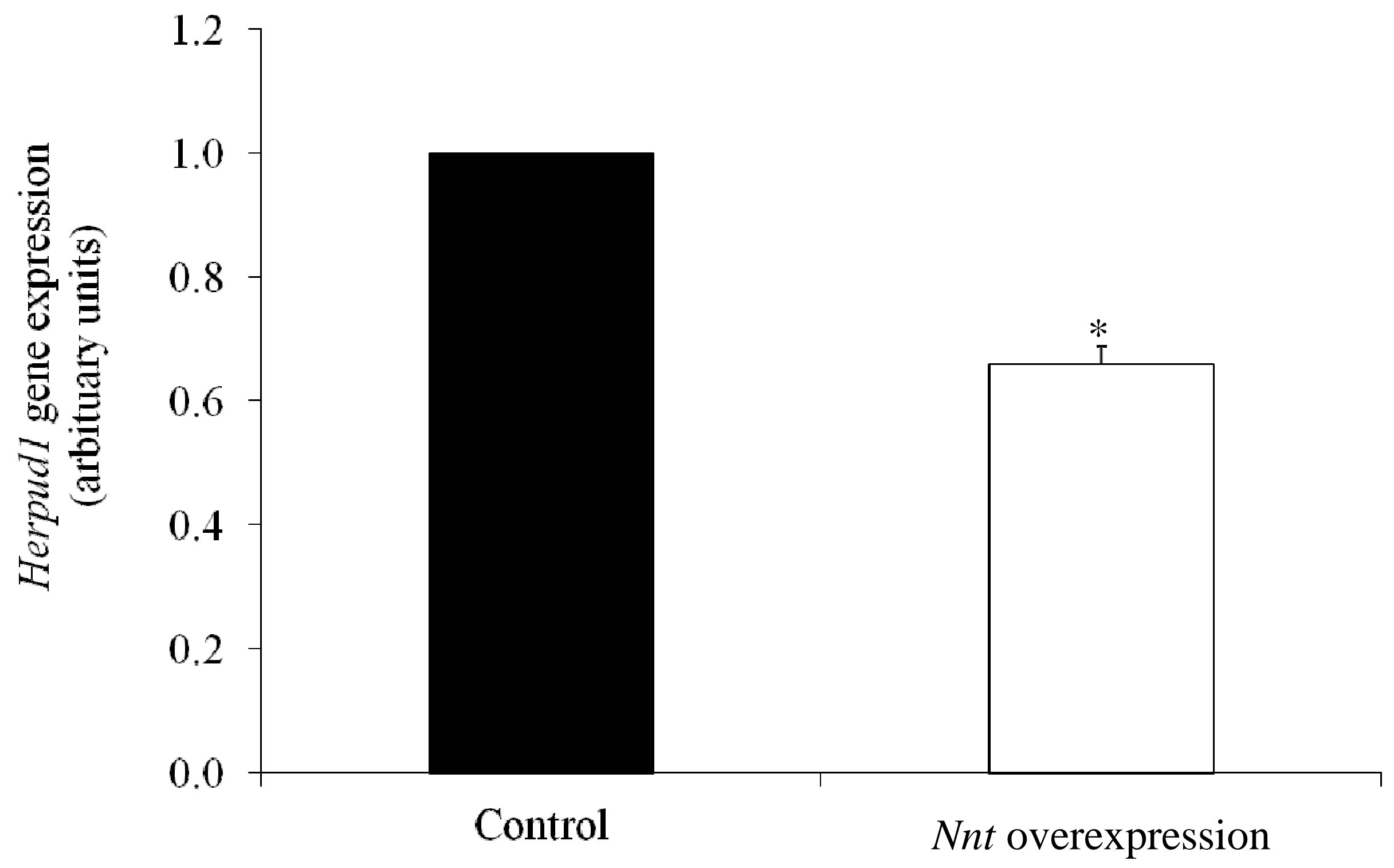

Figure 4 


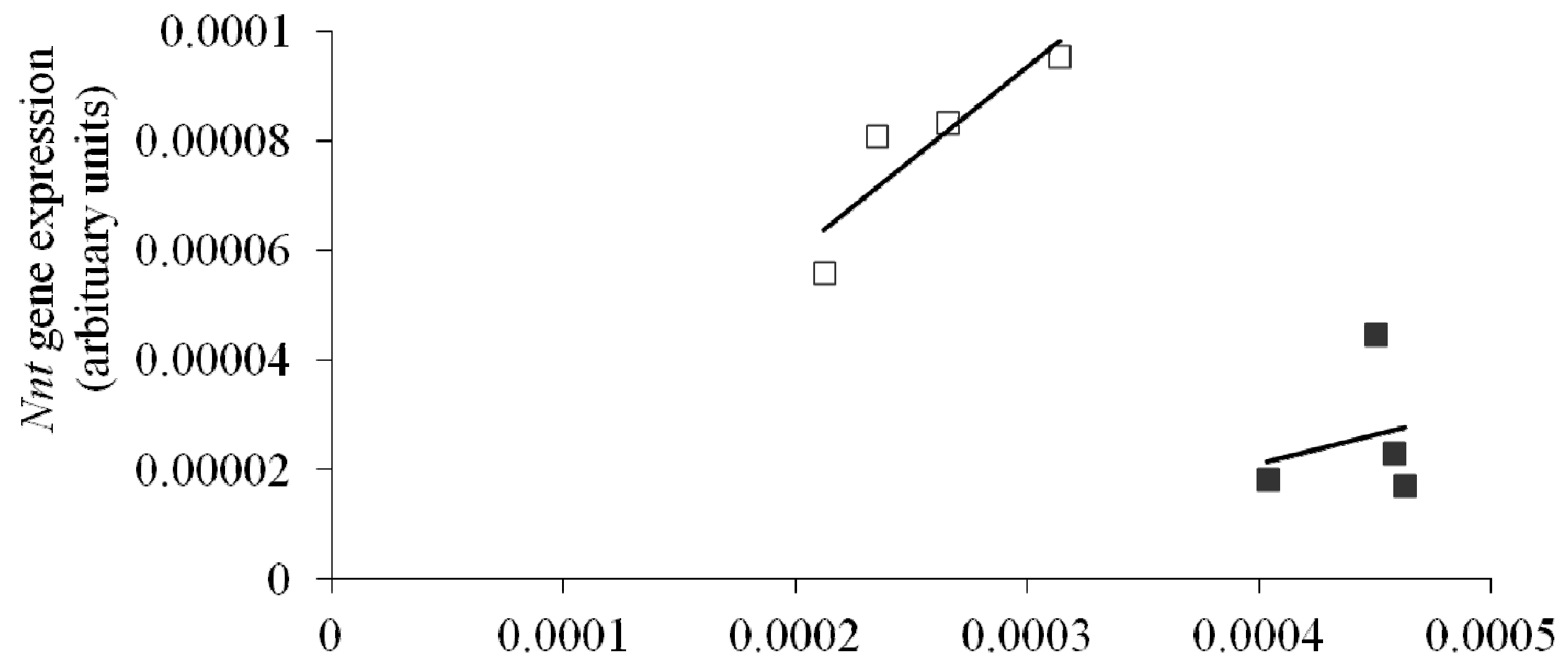

Herpudl gene expression (arbituary units)

Figure 4 


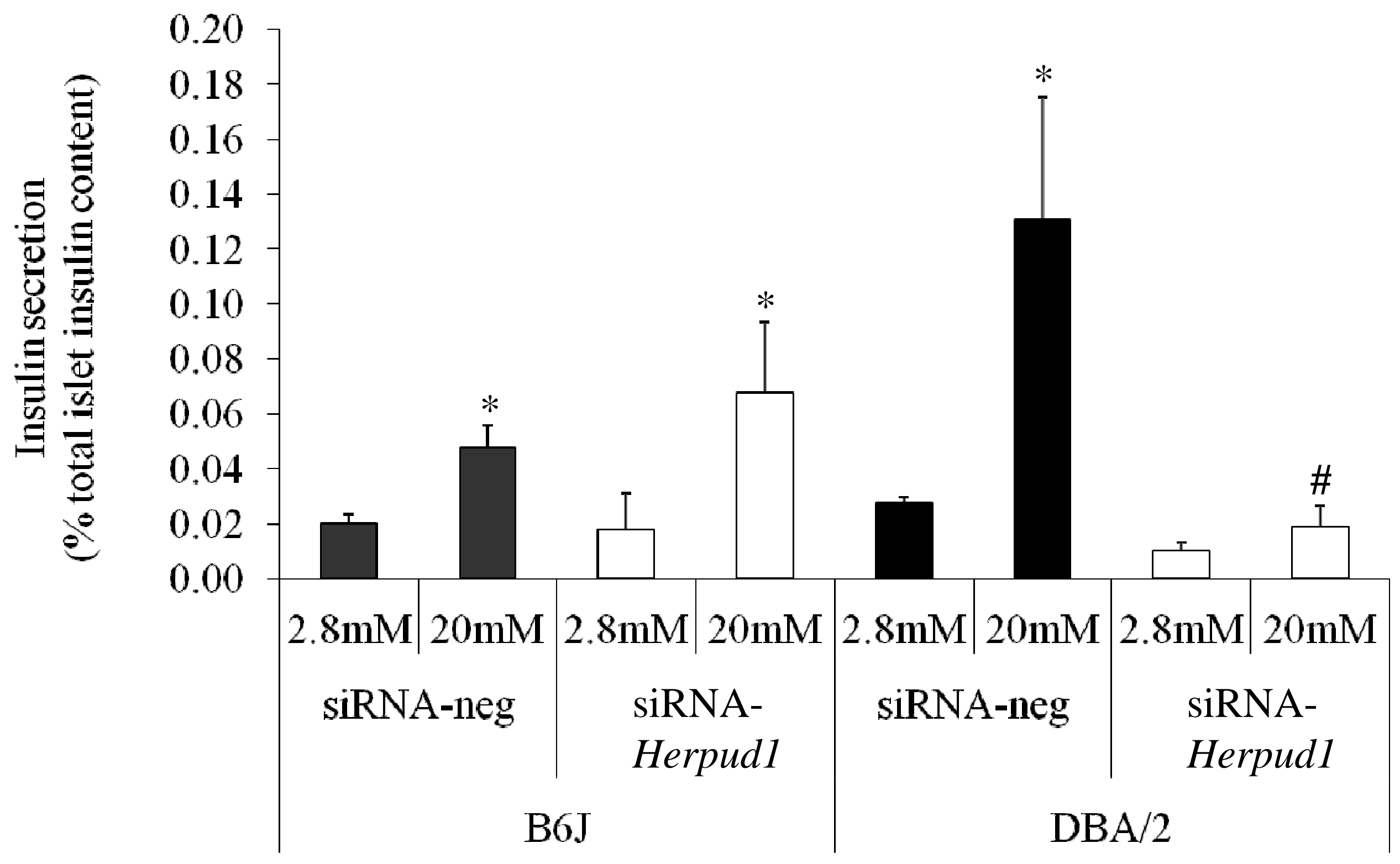

Figure 5 
b

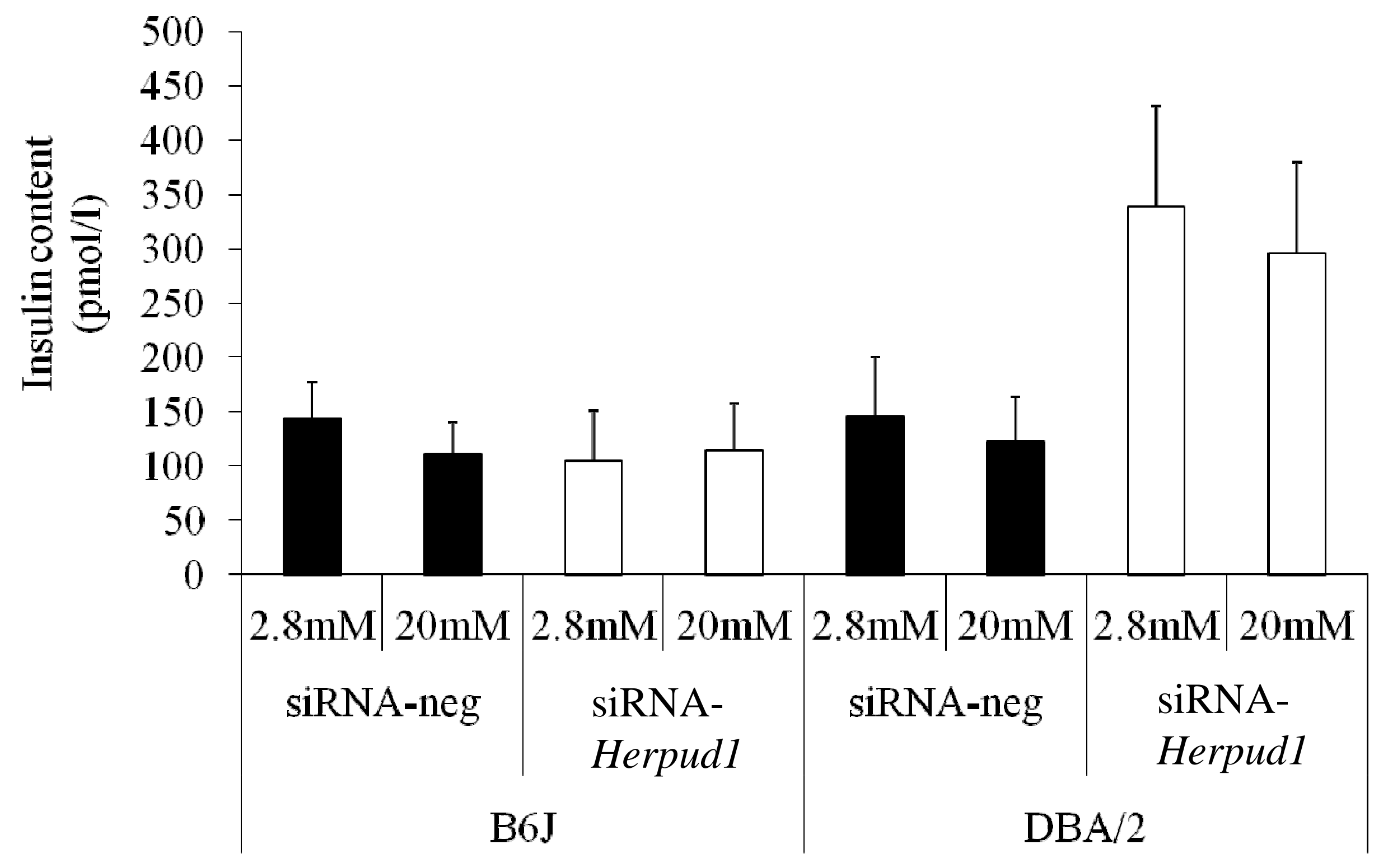

Figure 5 




Figure 5 
d

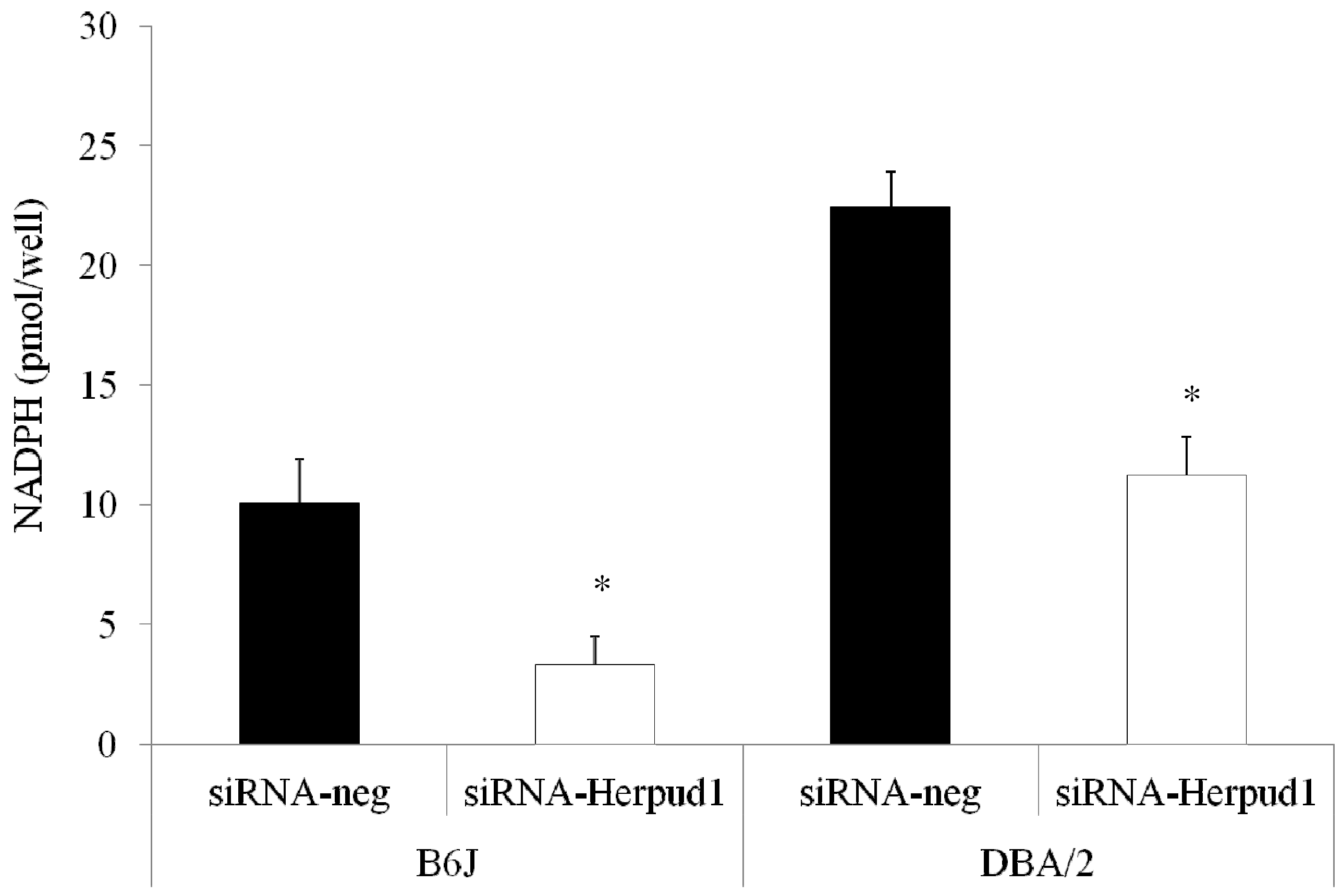

Figure 5 


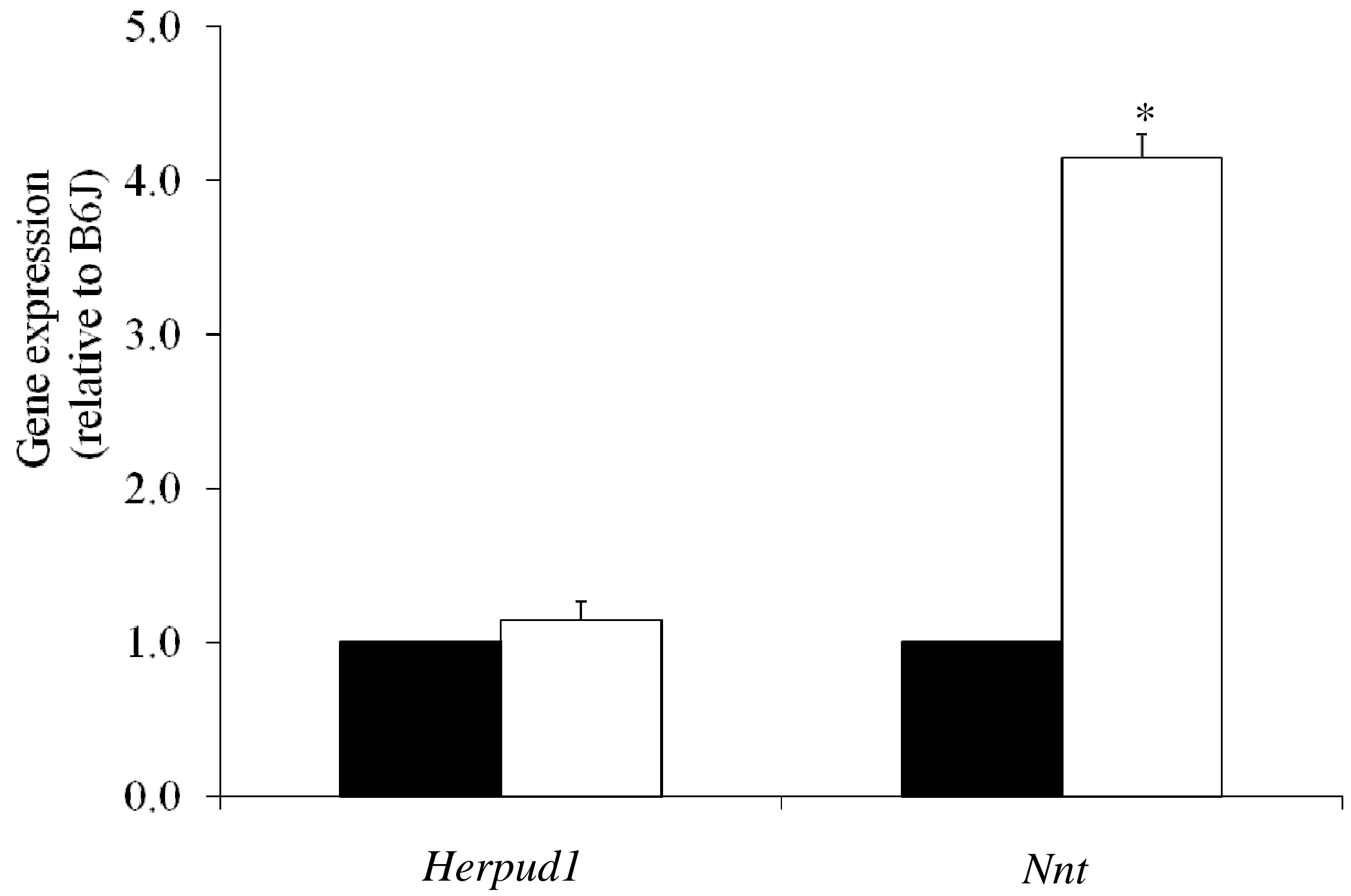

Figure 5 
Neg Herpudl Neg Herpudl


44 kDa HERP

$50 \mathrm{kDa} \alpha$-tubulin

Figure 5 


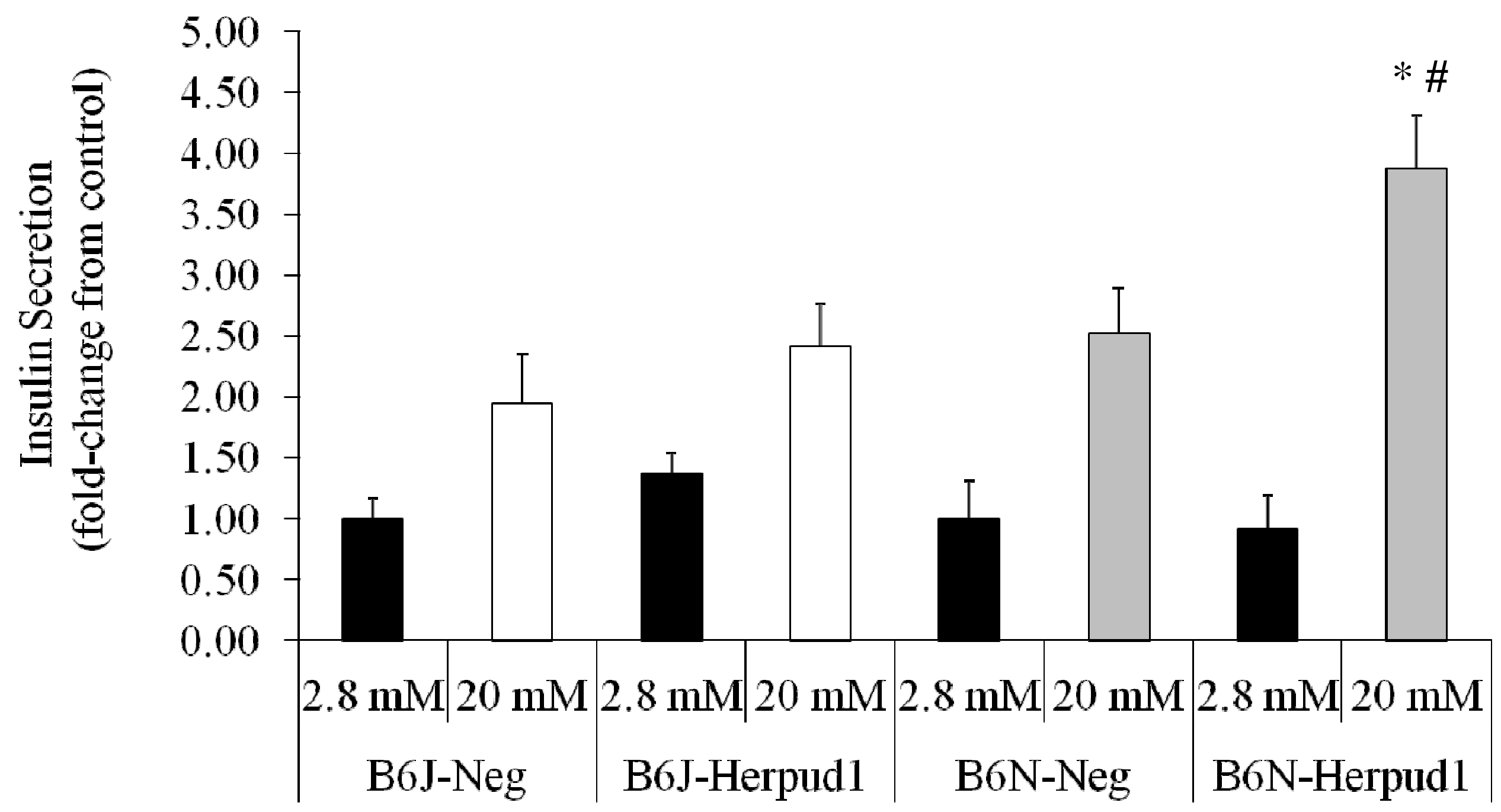

Figure 5 
Fasting plasma glucose $(\mathrm{mmol} / \mathrm{l}) \curvearrowright$

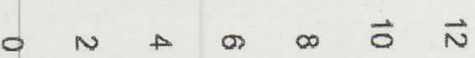

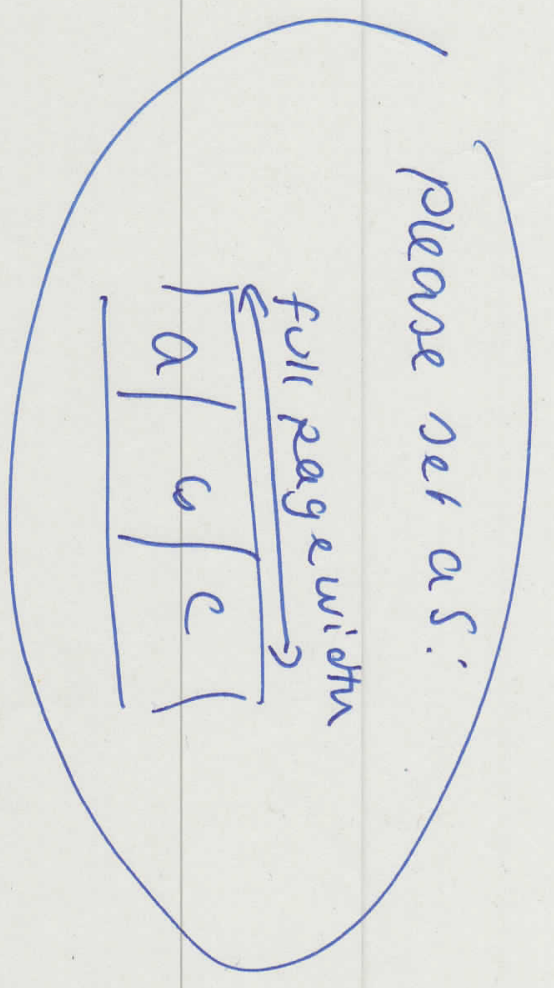

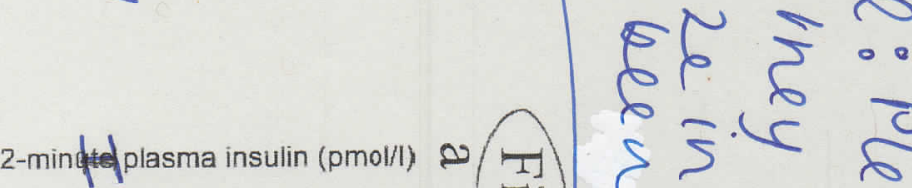
- Na O $\infty \overrightarrow{0} \vec{N} \vec{A} \vec{O} \vec{\infty}$



BXD96



$27+\frac{2}{2}$

ह2, 2

$6 \leqslant+8$

80

यद.

ईह 5 के

$8 \pi \frac{5}{5}$.

f. 5 ?

a.?

$8 \int^{8} 8$

800

$E-2$

$8 \pi$

ह 65

60

8
$8+1$

$\frac{8}{\varepsilon} \leqslant$

$\overrightarrow{2}>\hat{2}$

$>08$

2

ร. $]$

660

$62 \leqq$

- 5

$4 \sqrt{c}$
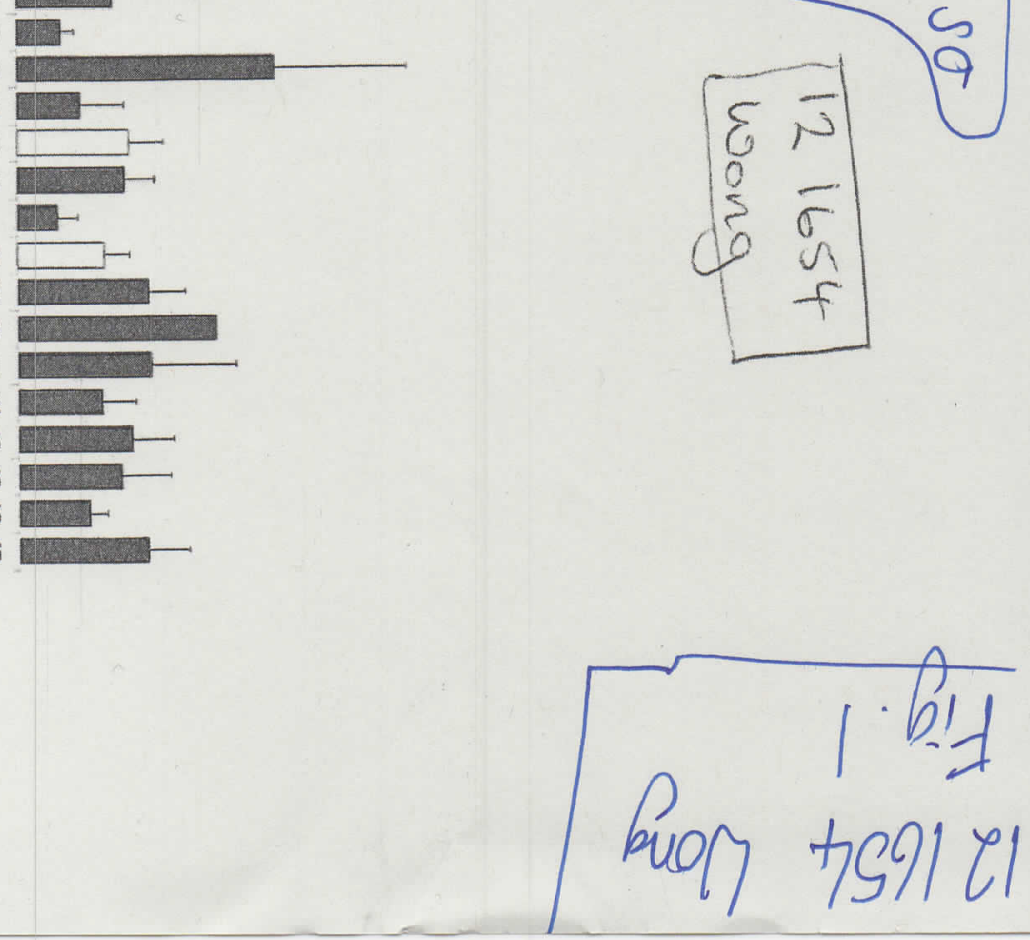


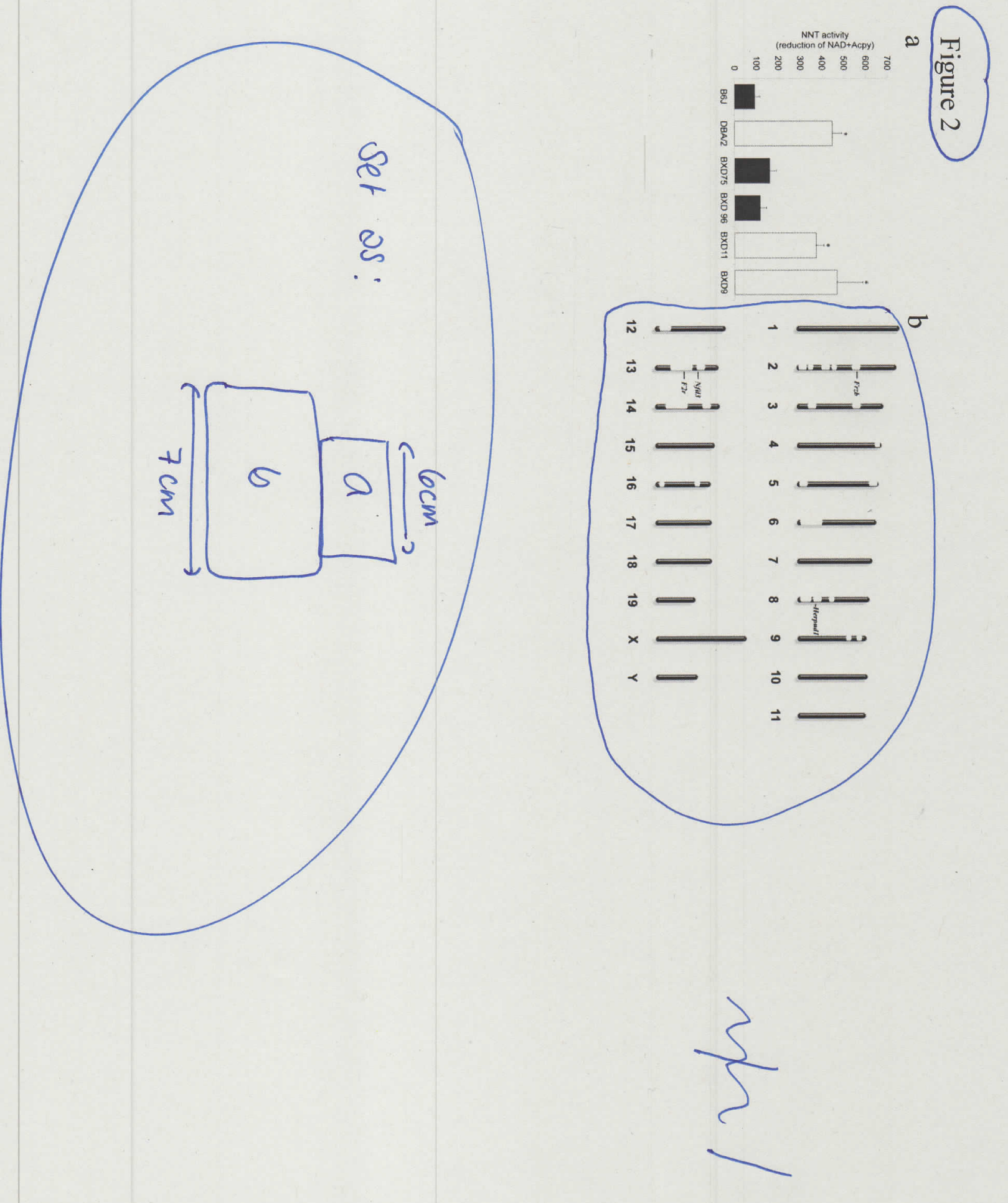



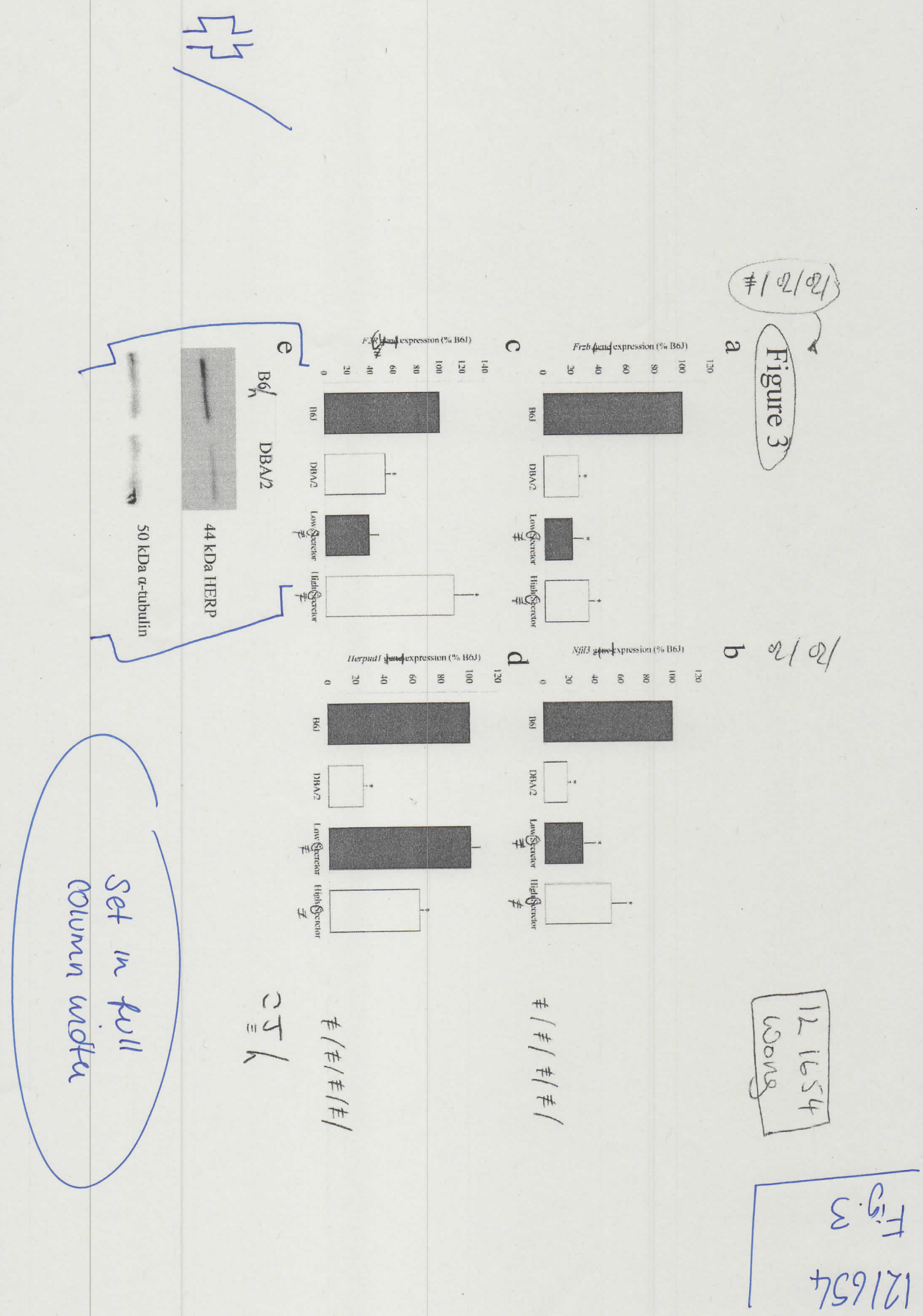


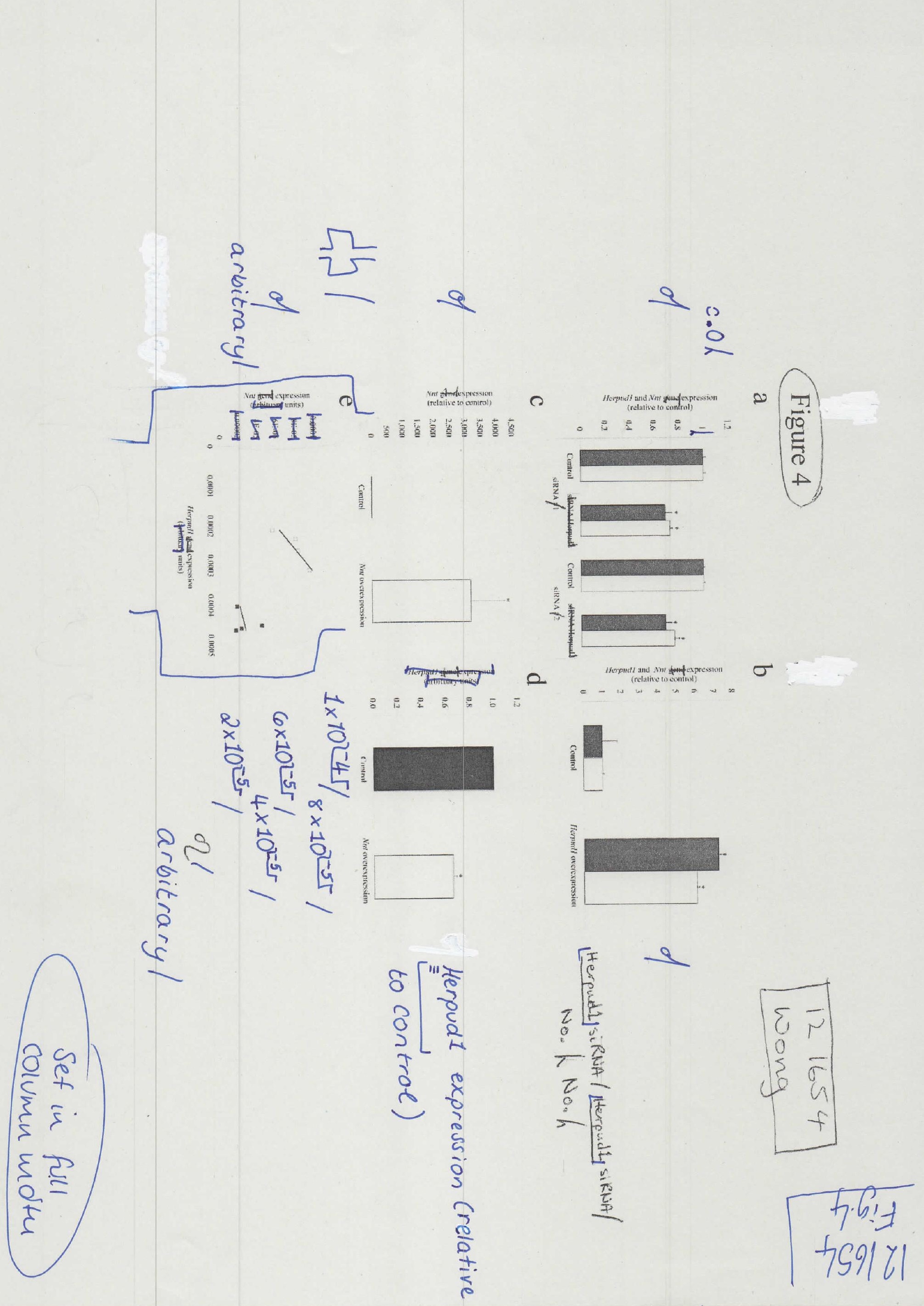




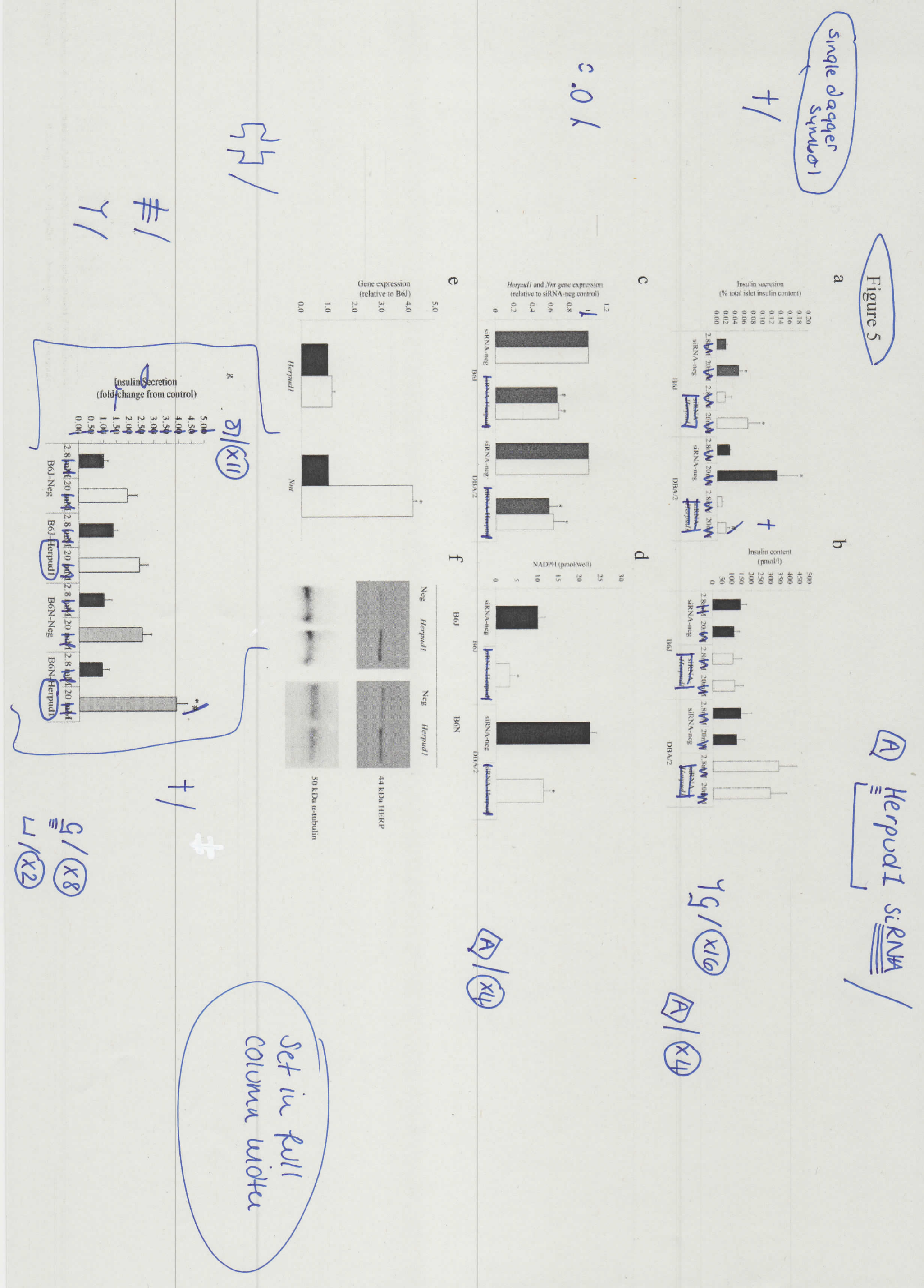

